\title{
Study on Polishing DF2 (AISI O1) Steel by Nd: YAG Laser
}

\author{
Kelvii Wei GUO \& Hon Yuen TAM \\ Department of Mechanical and Biomedical Engineering \\ City University of Hong Kong, 83 Tat Chee Avenue \\ Kowloon Tong, Kowloon, Hong Kong \\ Tel: 852-3442-4621_E-mail: guoweichinese@yahoo.com; metamhy@cityu.edu.hk
}

\author{
Received: August 24, 2011 Accepted: September 12, $2011 \quad$ Published: January 1, 2012 \\ doi:10.5539/jmsr.v1n1p54 \\ URL: http://dx.doi.org/10.5539/jmsr.v1n1p54
}

\begin{abstract}
Pulse Nd: YAG laser was used to polish DF2 cold work steel. Influence of irradiation parameters on the 3D surface topography was studied by $3 \mathrm{D}$ profilometer, scanning electron microscopy (SEM), and atomic force microscope (AFM). Results among the tests showed when DF2 specimens were irradiated with parameters of (i) laser input energy $\mathrm{P}=1 \mathrm{~J}$, (ii) pulse feedrate $=300 \mathrm{~mm} / \mathrm{min}$, (iii) pulse duration $\mathrm{PD}=3 \mathrm{~ms}$, and (iv) pulse frequency $f=20 \sim 25 \mathrm{~Hz}$, laser polishing of DF2 cold work steel seemed to be successful. Also, effect of laser polished parameters on the laser polishing temperature was described and the analysis of temperature field of laser polishing was herewith proposed. It demonstrated that for a given laser, influence of laser pulse feedrate was more prominent than that of other parameters on the topography of a laser polished surface. Moreover, the mechanism of laser polishing relied on the heat-input interaction with the base metal. When $\mathrm{H}_{\text {input }}=\mathrm{H}_{\text {threshold, }}$, the mechanism of laser polishing principally relied on the metal melting; When $\mathrm{H}_{\text {input }}>\mathrm{H}_{\text {threshold }}$, the mechanism of laser polishing was a combination of metal evaporation and melting; and when $\mathrm{H}_{\text {inpul }}>>\mathrm{H}_{\text {threshold }}$, the mechanism of laser polishing mainly relied on the metal evaporation.
\end{abstract}

Keywords: Laser polishing, DF2, Surface topography/morphology

\section{Introduction}

Dies and moulds used in the fabrication of metal, glass and plastic products require a high quality surface finish. Some surface improvement, of easily accessible areas, can be carried out using small rotary abrasive wheels or vibrating tools. However, the majority of the surface finishing operations applied to these dies and moulds are manual. The finishing or polishing is based on the use of abrasive cloths or papers of successively decreasing abrasive particle size culminating in the buffing of the mould with impregnated cloth.

Operator shortcomings cause these manual polishing methods to have a number of limitations. The operator has to be trained in suitable techniques and the effective application of these techniques and for polishing flat small radii requires considerable experience. Consistency and repeatability are also required. For example, a skilled worker can be required to spend ten days polishing ten complex dies and needs to ensure that, on completion, all the dies are identical. Finally, it is important that, in the achievement of the polished surface, there is no loss of dimensional accuracy. Consequently, a trained and experienced worker, skilled in polishing, becomes an expensive but essential part of the manufacturing process.

The process is also extremely time-consuming. It has been reported that the polishing time of a mould can represent up to $37 \%$ of the total production time of the entire mould (Steen, 2003). Improvement in the finishing or polishing of the mould or die to lessen the input of a skilled operator or to reduce the processing time has the potential to dramatically reduce the cost of the finished item.

Whilst automated processes, suitable for the polishing of closed dies, they are limited in their application. For example, precision machining using a single point diamond tool is slow, requires conditions not readily available in an industrial environment and is limited to flat surfaces (Steen, 2003; Kurt et al., 1997; Ryk, Kligerman \& Etson, 2002). Chemical polishing and electrochemical polishing are limited in their application and can be difficult to control (Ryk, Kligerman \& Etson, 2002). Some research has been carried out into the use of robot controlled polishing tools (Steen, 2003; Ryk, Kligerman \& Etson, 2002; Lugomer, 1990; Duley, 1983). However, the use of a rotary wheel or ultrasonic chisel requires that the wheel axis or angle of the chisel is almost parallel 
to the surface being polished. This limits the application to almost flat workpieces.

Controlled material removal can be achieved by the use of ultrasonic machining (Steen, 2003; Ryk, Kligerman \& Etson, 2002). In this process, the workpiece material is removed by the high frequency hammering of abrasive particles, in the form of the water-based slurry, into the workpiece surface. By the use of suitably formed tools, complex shapes can be created in the workpiece. As a potential method of polishing closed dies, this machining method has the disadvantage that it is normally used for fixed location drilling or workpiece indentation.

Abrasive flow machining is currently used in industrial applications to successfully and efficiently polish open dies. It uses a mix of abrasive particles suspended in a pliable polymer base. This mix is hydraulically powered over the surface to be polished. The process is however normally restricted to the polishing of open dies which are tubular or hollow in form with an entry and exit for the flowing mix (Steen, 2003; Kurt et al., 1997).

It is well known that high power lasers are presently used for a variety of machining application especially to process exotic materials. These materials range from metals to non-metals including ceramics. Basically, laser machining is a highly localized thermal processing.

Now, Laser is widely used as a machine tool to modify the surface of the engineering materials, such as laser surface alloying, laser cladding, surface texturing, laser physical vapor deposition etc (Steen, 2003; Lugomer, 1990; Duley, 1983). In recent years, laser polishing is becoming an attractive new technique to polish diamond, lens and so on (Kurt et al., 1997; Ryk, Kligerman \& Etson, 2002; Lugomer, 1990; Duley, 1983).

By considering the unique characteristics of the laser radiation and excellent non-contact micromachining possibility with the laser, an attempt has been made to polish DF2 steel employing the concepts of micromachining (Guo, 2009; Guo, 2007). As a powerful surface modification technique, it is imperative to investigate on the laser polishing of metals systematically.

\section{Experimental Material and Procedures}

\subsection{Experimental Material}

The chemical composition of DF2 cold work steel was shown as Table 1.

\subsection{Experimental Procedures}

The materials were machined into $10 \mathrm{~mm} \times 10 \mathrm{~mm} \times 25 \mathrm{~mm}$, which had surface roughness of $0.2,0.4,0.6 \mu \mathrm{m}$, and its corresponding initial 3D surface morphologies were measured by Surface Texture Tester/Form Talysurf PGI

The specimens were carefully cleaned by acetone and pure ethyl alcohol to remove any contaminants on its surface. The initial morphology of $0.4 \mu \mathrm{m}$ and its corresponding SEM surface image are shown in Fig. 1. Figure 2 illustrates the microstructure of DF2 steel (AISI O1). A GSI Lumonics Model JK702H Nd:YAG TEM 00 mode laser system, with wavelength of $1.06 \mu \mathrm{m}$, defocused distance of $15 \mathrm{~mm}$, and focus spot diameter of approximately $1.26 \mathrm{~mm}$, was used to irradiate the DF2 steel.

The different laser polishing conditions employed were as follows:

Polishing feedrate: $100,200,300,400 \mathrm{~mm} / \mathrm{min}$

Pulse energy: 1, 2, $3 \mathrm{~J}$

Pulse duration: $2,3,4,5,6 \mathrm{~ms}$

Pulse frequency: 15, 20, 25, $30 \mathrm{~Hz}$

After polishing, the surface morphology was observed by Taylor Hobson/Form Talysurf PGI. In order to understand mechanism of laser polishing, the generated morphology was observed by Scanning Electron Microscope (SEM) JEOL/JSM-5600.

\section{Results and Discussion}

\subsection{Influence of Relative Irradiating Speed (feedrate) Between Laser and Workpiece}

Although laser irradiated surface removed most high plateaus from the original surface of the specimens (cf. Fig. 1(a) and Fig. 3), improper setting of irradiation might roughen surface rather than smoothening it. Laser irradiation with original surface roughness $R \mathrm{a}=0.4 \mu \mathrm{m}$ under different feedrates with operational conditions of pulse energy $1 \mathrm{~J}$, frequency $25 \mathrm{~Hz}$ and pulse duration $3 \mathrm{~ms}$ (Fig. 3) suggested that there was an optimal feedrate in achieving smoothest surface 3D morphology, which was at $300 \mathrm{~mm} / \mathrm{min}$. As the variation of morphology for this particular study (Fig. 3) illustrated that the smoother surface was obtained when feedrate increased from 100 $\mathrm{mm} / \mathrm{min}$ to $300 \mathrm{~mm} / \mathrm{min}$, and it became coarser once again when it was above $300 \mathrm{~mm} / \mathrm{min}$. When the feedrate was above $300 \mathrm{~mm} / \mathrm{min}$, increasing the magnitude of feedrate led to unsmooth surface (Figs. 3(a) and (b)). When 
feedrate was below $300 \mathrm{~mm} / \mathrm{min}$, increasing in irradiation feedrate improved the surface topography (Figs. 3(c) and (d)).

Figure 4 shows the relationship between the arithmetic mean surface roughness $R$ a and the relative moving speed (feedrate) between the irradiating laser and the irradiated specimen. Results indicated that the initial increase in feedrate accompanied with the decrease in surface roughness until the feedrate reached $300 \mathrm{~mm} / \mathrm{min}$ at which the surface roughness was the minimum. Then, further increase in the feedrate increased the roughness once again. Measurements illustrated that the surface roughness of irradiated specimens was to certain extend getting smoother along the irradiation path except with those specimens having surface roughness $R \mathrm{a}=0.2 \mu \mathrm{m}$. For those DF2 steel specimens with $R \mathrm{a}=0.6 \mu \mathrm{m}$, the roughness of the irradiated surfaces was consistently and evidently deceased inspire of whether the relative feedrate being at or exceeding $300 \mathrm{~mm} / \mathrm{min}$. For those specimens with $R \mathrm{a}=0.4 \mu \mathrm{m}$, the irradiated surface roughness was generally higher than their initial condition when the relative feedrate was below $300 \mathrm{~mm} / \mathrm{min}$. However, it decreased with the increase in the relative feedrate. When the relative feedrate was at $400 \mathrm{~mm} / \mathrm{min}$, the irradiated roughness was increased to some level. For those DF2 tool steel specimens with $R \mathrm{a}=0.2 \mu \mathrm{m}$, the irradiated roughness was consistently higher than their initial value within the various feedrates in the experimental studies.

\subsection{Influence of Laser Irradiating Pulse Energy}

\subsubsection{Influence of Laser Irradiating Pulse Energy on Surface Topography}

As studies in Sec. 3.1 giving optimal surface at the feedrate of $300 \mathrm{~mm} / \mathrm{min}$, subsequent studies were performed with this feedrate. Figure 5 shows the effect of laser irradiating energy on surface topography. Generally, increase in pulse energy simultaneously raised up the heat input to the surface substrate. Too high of the pulse energy was likely to melt the surface of substrate which subsequently changed the surface topography and mechanical properties of the DF2 steel specimens. When compared with the originally machined surface of $\mathrm{Ra}=$ $0.4 \mu \mathrm{m}$ (Fig. 1(b)), its treated surface (Fig. 5(a)) irradiated under a feedrate $=300 \mathrm{~mm} / \mathrm{min}, f=25 \mathrm{~Hz}, \mathrm{PD}=3 \mathrm{~ms}$ and pulse energy $=2 \mathrm{~J}$ gave the coarser surface. And, its further magnified counterpart (Fig. 5(b)) showed sign of some micro-pits and round agglomerates loosely scattering over both troughs and crests on the surface. Those round agglomerates would be the nucleus for re-solidifying the melt and subsequent shrinkage led to some locations slightly sinking below their surrounding material. Such surface topography with scattering of micro-pits and micro ball-like features (Fig. 5(b)) implied that there was some level of change of properties of DF2 surface. This change was not really anticipated since it was initially expected, from Fig. 5(a), that the properties of the original surface topography at pulse energy of $2 \mathrm{~J}$ would be the same as its as-received condition. At higher pulse energy (i.e. $3 \mathrm{~J}$ ), except those originally machining grooves ridges (Fig. 5(c)) that scattering on the irradiated surface with shallower depth, more severe melting and re-solidification were observed. A large amount of microholes and weblike cracks were distributed on the polished surface (Figs. 5(c) and 5(d)). Such melting and re-solidification (Fig. 5(d)) changed the properties of the initial surface drastically resulted in the failure of polishing.

\subsubsection{Influence of Laser Pulse Energy on Surface Roughness}

Figure 6 shows the textures of a surface irradiated at various pulse energies. Basically, the surface gradually became coarser when pulse energy was increasing. Figure 7 plots the experimental data of the laser pulse energy and the irradiated surface roughness. It showed the surface roughness increased with the irradiated pulse energy. At pulse energy of $2 \mathrm{~J}$, the measured surface roughness was $0.49 \mu \mathrm{m}$ as a result of the appearance of those protrusions on the surface (see Fig. 6(a)). The surface roughness approximately increased to $0.7 \mu \mathrm{m}$ when the pulse energy was increasing further because of the occurrence of more prominent protrusions on the irradiated surface. Furthermore, the width of the laser irradiated band became larger as observed in Fig. 6(b), implying that laser polishing at pulse energy at and above $2 \mathrm{~J}$ under the setting conditions was generally not achievable.

\subsection{Influence of Laser Irradiation Frequency (Repetition Rate)}

\subsubsection{Influence on Surface Topography}

Result (Fig. 8) shows that the increase in pulse frequency generally led the topography of the irradiated surface to become smoother and smoother. But, the irradiated surface became coarser when the pulse frequency was over $25 \mathrm{~Hz}$, as shown in Fig. 8.

\subsubsection{Influence on Surface Roughness}

Figure 9 shows the laser irradiated surface scanned at various pulse frequencies. It showed that the roughness of the irradiated surface decreased with the pulse frequency. At a pulse frequency above $25 \mathrm{~Hz}$, the increase in the roughness of the irradiated surface resulted in a coarser irradiated surface. 
Figure 10 shows the corresponding relationship between the pulse frequency and the irradiated roughness. It illustrated that the roughness of the irradiated surface was below $0.4 \mu \mathrm{m}$ when the pulse frequency was in the range of $20 \mathrm{~Hz}$ to $25 \mathrm{~Hz}$, which gave the minimum value of roughness value. When the pulse frequency was above $25 \mathrm{~Hz}$, the roughness of the irradiated surface was increasing with again, implying that the irradiated surface became coarser when the pulse frequency was either below $20 \mathrm{~Hz}$ or above $25 \mathrm{~Hz}$.

\subsection{Influence of Laser Polishing Pulse Duration (PD)}

\subsubsection{Influence on Surface Topography}

Figure 11 illustrates the influence of pulse duration on the polished surface roughness and topography. It showed the non-uniform changes of the surface topography irradiated at different pulse durations. The variation of the topography of the surface irradiated at shorter pulse duration was usually detected markedly. It was observed that the DF2 surface was polished effectively when the pulse duration was in the range of $3 \mathrm{~ms}$ and $4 \mathrm{~ms}$. With longer pulse duration, some level of micro-scale melted ridges was seen (Figs. 11(d) and 11(e)). In the present study, the Nd:YAG laser was irradiating the substrate that was moving relatively with a constant feedrate. The inputting laser energy at any location along the irradiated path on the substrate was the summation of (i) the energy per pulse at the irradiation point and (ii) the accumulated energy due to the effect of overlapping of the successive focusing spots along irradiation path and the heat transfer from its neighboring spots within a specific pulse frequency prior to the reaching of quasi-steady.

\subsubsection{Influence on Surface Roughness}

Figure 12 shows the relationship of the measured roughness and pulse duration. It showed that the decrease in pulse duration reduced the roughness of the irradiated surface correspondingly. At the pulse duration of $3 \mathrm{~ms}$, the irradiated surface roughness among the tests reached its minimum value. When the pulse duration was lower than $3 \mathrm{~ms}$, the roughness of irradiated surface started to increase again to some respective level. It was observed that the irradiated surface became rougher at longer pulse duration of $4 \mathrm{~ms}$, which typically illustrated the effect of longer pulse duration on the irradiated surface.

\subsection{Surface Morphology}

Figure 13(a) showed the morphology of polished surface, and its corresponding SEM was shown in Fig. 13(b). It indicated that the polished surface was smoother than its initial surface. According to Fig. 13(a), it demonstrated that there were some small ridges on the polished surface. Compared Fig. 13(b) with Fig. 1(b), the grooves on the surface became shallower, together with thinner ridges. The big ridges could not be detected and the bulky chippings disappeared, resulted in smoother polished surface shown as Fig. 13(a). Moreover, the initial surface morphology had been properly maintained and no cracks can be found on the polished surface.

\subsection{Laser Polishing Texture}

Figure 14 shows the initial cross-section micrograph of the specimen before polishing. It could be seen that the surface of specimen was uneven as shown distinctly in Fig. 14(b) (dash line), which had the poor finish of mould surface in the tool machining.

Figure 15 illustrates the schematic diagram of cross-section of polished specimen, where A to D stood for the different zones affected by laser polishing. Its corresponding cross-section micrograph of polished specimen was shown in Fig. 16. The alteration could be observed obviously. The polished surface was significantly improved by laser polishing resulted in smoother surface with microstructure changed as shown in the left of Fig. 16(a). The zone A had been known to be a hardened layer with some of the spheroidized carbide particles enlarged to some extent as shown in the Fig. 16(a). As zone B, finer spheroidized carbide particles dispersed in the matrix of ferrite resulted in improving the higher properties of mold applications (cf. Figs. 16(a) and (b). It was well known the zone $\mathrm{C}$ was the heat affect zone (HAZ) as shown in Figs. 16(b) and (c). The zone D was the microstructure of DF2 steel. Contrasted zone $\mathrm{C}$ with zone $\mathrm{D}$, it illuminated that the microstructure of zone $\mathrm{C}$ was nearly same as zone $\mathrm{D}$, it indicated that the heat input into the base metal was too low to affect the mechanical properties of DF2 to large scale during the laser polishing. According to Fig. 16(a), it depicted the average thickness of the zone A and B was approximately $40 \mu \mathrm{m}$, where the average thickness of the zone A was about 10 $\mu \mathrm{m}$. As a result, the polished surface was suitable for industry application.

Figure 17 shows that there were a plenty of micro-pits and melted substrate micro-balls scattered both on the polished surface (cf. Figs. 13(b) and 17) which could efficiently improve their load carry capacity and permit ease of release (Guo, 2009; Guo, 2007; Jastrzebski, 1987). 


\section{Mechanism of Laser Polishing}

\subsection{Temperature Field of Laser Polishing}

The heat is assumed to be released instantaneously at time $t=0$ on the surface of the substrate. This causes a temperature rise in the material as follows (Steen, 2003; Duley, 1983; Mills, 1995; Janna, 1986):

$$
T-T_{0}=\frac{Q}{\rho c(4 \pi \alpha t)^{\frac{3}{2}}} \exp \left(\frac{-R^{2}}{4 \alpha t}\right)
$$

where $\rho$ is the material density, $C$ is specific heat, $\alpha$ is thermal diffusivity, $R$ is the distance between the heat resource and the observed point, $Q$ is the input energy.

When temperature distribution is quasi-steady state, where $v$ is the velocity of the moving heat, $x$ is the distance between the heat resource and the observed point along the polishing direction:

$$
T-T_{0}=\frac{q_{O}}{2 \pi \rho c \alpha R} \exp \left(-\frac{v}{2 \alpha}(R+x)\right)
$$

During the Nd:YAG laser polishing, $q_{0}$ can be expressed as

$$
q_{0}=\eta(N(f, v)) \times \frac{P}{\frac{\pi D^{2}}{4} \times P D}=\eta(N(f, v)) \times \frac{4 P}{\pi D^{2} \times P D}
$$

Where

$\eta(N(f, v))$ is the coefficient of laser polishing input energy, which is direct proportional to number of overlaps or pulse frequency. With number of overlaps increasing, or pulse frequency increasing with constant the feedrate, $\eta(N(f, v))$ will be increased synchronously. With the velocity (feedrate) increasing, number of overlaps with the constant pulse frequency will be decreased correspondingly led to lower heat input, $\eta(N(f, v))$ will be decreased accordingly.

Eq. (2) can be rewritten as:

$$
T-T_{0}=\frac{2 \times \eta(N(f, v)) \times P}{\pi^{2} D^{2} \rho c \alpha R \times P D} \exp \left(-\frac{v}{2 \alpha}(R+x)\right)
$$

Define $\xi=\frac{1}{2 \pi \rho c \alpha}$, then Eq. (4) can be written as:

$$
T-T_{0}=\frac{\xi \times \eta(N(f, v)) \times P}{\frac{\pi D^{2}}{4} \times P D \times R} \exp \left(-\frac{v}{2 \alpha}(R+x)\right)
$$

Define

$$
q=\frac{P}{\frac{\pi D^{2}}{4} \times P D}
$$

then Eq. (6) can be written as

$$
T-T_{0}=\frac{\xi \times \eta(N(f, v)) \times q}{R} \exp \left(-\frac{v}{2 \alpha}(R+x)\right)
$$

Define:

Dimensionless temperature:

$$
\omega_{T}=\frac{T-T_{0}}{T_{r}-T_{0}}
$$

where $T_{r}$ is the reference temperature. 
Define:

Dimensionless operating parameter:

$$
\kappa=\frac{\eta(N(f, v)) q v}{4 \pi \alpha^{2} \rho c\left(T_{r}-T_{0}\right)}
$$

Dimensionless x-coordinate:

$$
\omega_{x}=\frac{v x}{2 \alpha}
$$

Dimensionless y-coordinate:

$$
\omega_{y}=\frac{v y}{2 \alpha}
$$

Dimensionless z-coordinate:

$$
\omega_{z}=\frac{v z}{2 \alpha}
$$

Dimensionless radius vector:

$$
\omega_{r}=\frac{v R}{2 \alpha}
$$

Substituting these parameters into Eq. (7), then it can be gained:

$$
\omega_{T}=\frac{T-T_{0}}{T_{r}-T_{0}}=\kappa \frac{1}{\omega_{r}} \exp \left(-\omega_{r}-\omega_{x}\right)
$$

or

$$
\frac{\omega_{T}}{\kappa}=\frac{1}{\omega_{r}} \exp \left(-\omega_{r}-\omega_{x}\right)
$$

Then the isothermal zone widths can be gotten just as fellows.

The maximum width of an isothermal enclosure is obtained by setting:

$$
\frac{\partial \ln \left(\frac{\omega_{T}}{\kappa}\right)}{\partial \omega_{r}}=\frac{\partial \ln \left(\frac{\omega_{T}}{\kappa}\right)}{\partial \omega_{x}} \frac{\partial \omega_{x}}{\partial \omega_{r}}=0
$$

where $\frac{\partial \omega_{x}}{\partial \omega_{r}}=\frac{\partial \omega_{x}}{\partial \sqrt{\omega_{x}+\omega_{y}+\omega_{z}}}=\frac{\omega_{r}}{\omega_{x}}$

Hence Eq. (16) will be transformed into:

i.e.

$$
\frac{\partial \ln \left(\frac{\omega_{T}}{\kappa}\right)}{\partial \omega_{r}}=\left(\left(-\frac{\omega_{x}}{\omega_{r}^{2}}-\frac{\omega_{x}}{\omega_{r}}-1\right) \frac{\omega_{r}}{\omega_{x}}\right)_{m}=\left(-\frac{1}{\omega_{r}}-1-\frac{\omega_{r}}{\omega_{x}}\right)_{m}=0
$$

$$
\omega_{x m}=-\frac{\omega_{r m}^{2}}{\omega_{r m}+1}
$$

Substituting $\omega_{x m}$ into Eq. (15), then it should be attained:

$$
\frac{\omega_{T_{m}}}{\kappa}=\frac{1}{\omega_{r m}} \exp \left(-\omega_{r m}-\omega_{x m}\right)=\frac{1}{\omega_{r m}} \exp \left(-\frac{\omega_{r m}}{\omega_{r m}+1}\right)
$$


Eq. (15) shows that the relationship between the laser polishing temperature and the polishing parameters, such as pulse energy, pulse duration, pulse frequency, velocity (feedrate) etc.. It can be seen that with the pulse energy and pulse frequency increasing, the polishing temperature will be higher. However, with the pulse duration and velocity (feedrate) increasing, the polishing temperature will be decreased. Furthermore, when the velocity (feedrate) is increased, $\eta(N(f, v))$ will be decreased synchronously, therefore, the polishing temperature will be decreased seriously. Furthermore, according to Eq. (13) and Eq. (19), it indicated that the velocity (feedrate) has more remarkably impact on the polishing temperature of the given points. Therefore, there is a certain heat-input threshold with a certain pulse feedrate, pulse energy, pulse duration and pulse frequency for laser polishing.

\subsection{Effect of Laser Polishing Feedrate and Pulse Frequency}

4.2.1 Effect of Laser Polishing Feedrate and Pulse Frequency on the Moving Distance of One Pulse and Overlap Percentage

It is well known that pulsed laser polishing is essentially a series of overlapping spots shown as Fig. 18, where $\delta_{1}$ is the moving-distance with pulse duration (PD), $\delta_{2}$ is the moving-distance of without pulse duration. The basic condition for the pulsed laser to realize polishing is that two continuous laser pulse spot should be tangential, viz.

$$
0<\delta \leq D
$$

where $D$ stands for the laser spot diameter, $\delta$ stands for the moving-distance of one pulse and

$$
\delta=\frac{\text { Feedrate }}{f}
$$

substitute Eq.(21) into Eq.(20), and then

$$
0<\frac{\text { Feedrate }}{f} \leq D
$$

that is

$$
0<\text { Feedrate } \leq D f
$$

According to Eq. (21), the relationship between $\delta$ and pulse frequency at various feedrates is shown as Fig. 19, and Fig. 20 is its corresponding overlap percentage of two continuous laser pulses. It shows that with the laser frequency increasing, the $\delta$ is decreased. Simultaneously, the overlap percentage is increased.

It can be found that under the conditions of feedrates and pulse frequencies in the experiment, the distances of one laser pulse $(\delta)$ are all lower than laser spot diameter $(D)$, which meets the Eq. (20) to realize the laser polishing. However, which parameters are suitable for laser polishing?

4.2.2 Effect of Laser Polishing Feedrate and Pulse Frequency on Effective Overlap Percentage and Number of Overlaps

In the viewpoint of geometry, when the distance of the moving laser irradiation spot is equal to or greater than the laser irradiation spot diameter, the process of laser polishing is quasi-steady state, shown as Fig. 21. The real line of different color stands for the laser spot during the power duration (PD), the dash line stands for the laser spot during the non-PD. The areas full of various colors stand for different overlapping numbers, such as the area in red color stands for one overlapped, the area in light yellow stands for two overlapped, etc. It can be obtained that

$$
\Delta=D-\left\|\frac{D}{\delta}\right\| \times \delta+\delta
$$

Where: $\Delta$ stands for the effective polishing size in central line.

Figure 22 shows the relationship between effective overlap percentage and pulse frequency at various feedrates. It can be seen that with the pulse frequency increasing, the trend of effective overlap percentage tends to decrease with wavy form. Moreover, with the feedrate increasing, the effective overlap percentage increases synchronously in principle, namely, (Effective overlap percentage $)_{400}>$ (Effective overlap percentage $)_{300}>$ (Effective overlap percentage $)_{200}>(\text { Effective overlap percentage })_{100}$. In addition, when the pulse frequency is $20 \mathrm{~Hz}, 21 \mathrm{~Hz}, 28 \mathrm{~Hz}, 29 \mathrm{~Hz}$ respectively, (Effective overlap percentage $)_{300}=($ Effective overlap

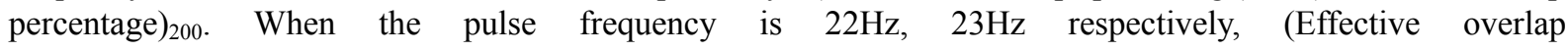
percentage $)_{300}=(\text { Effective overlap percentage })_{400}$. Furthermore, when the pulse frequency is $27 \mathrm{~Hz}$, (Effective overlap percentage $)_{400}<(\text { Effective overlap percentage })_{300}$. 
On the other hand, with the increasing of pulse frequency, number of overlaps will be increased simultaneously in terrace form shown as Fig. 23, and besides, with the feedrate increasing, number of overlaps will be decreased. According to Fig. 22, when the feedrate is $300 \mathrm{~mm} / \mathrm{min}$, and the pulse frequency is $20 \mathrm{~Hz}, 21 \mathrm{~Hz}$ respectively, the effective overlap percentage is approximately $20 \% \sim 25 \%$ and number of overlap is about 5 . Furthermore, Fig. 23 shows that when the feedrate is lower than $300 \mathrm{~mm} / \mathrm{min}$, number of overlaps is greater than 5 , especially when the feedrate is $100 \mathrm{~mm} / \mathrm{min}$, minimum number of overlaps is about 11 , which implies greater heat input into the base metal subsequently led to phase transformations and cracks in the surface layer resulted in poor properties of DF2 steel mold. In conclusion, considering the interaction of the effective overlap percentage and number of overlaps, there is a threshold of feedrate, when the feedrate is higher than the threshold, its number of overlaps is smaller, despite the effective overlap percentage is greater than that of other feedrates resulted in low heat affected on the surface. As a result, the surface of DF2 steel cannot be polished successfully. Contrarily, when the feedrate is lower than the threshold, number of overlaps will be increased markedly, though the effective overlap percentage is lower than that of other feedrates. Consequently, the heat input into the base metal will be higher led to microstructure change, phase transformation and cracks etc. on the laser polished surface. Therefore, the properties of DF2 steel mold will be decreased ultimately.

\subsubsection{Threshold of Laser Polishing Heat Interaction (Heat Input)}

In laser polishing metallurgical viewpoint, the lower heat input into the base metal is the better. In other words, when number of overlaps is small enough to polish the surface, and the effective overlap percentage inclined to null, the laser polishing will be of ideal. Consequently, it can be gotten that

$$
\left\|\frac{D}{N \delta}\right\|=0
$$

Substitute Eq. (21) into Eq. (25), then

$$
\left\|\frac{D \times f}{N \times \text { Feedrate }}\right\|=0
$$

where $\mathrm{D}=1.26 \mathrm{~mm}$.

Eq. (26) can be transformed into

$$
126 \times f=100 \times N \times \text { Feedrate }(f, N=1,2,3 \cdot)
$$

or

$$
\text { Feedrate }=\frac{D f}{N}=\frac{126 f}{100 N}(f, N=1,2,3 \cdot)
$$

where $N$ stands for number of overlaps.

When $N$ is equal to 1 , it means two continuous laser spots are tangential each other, the overlap percentage and effective overlap percentage are all equal to zero.

\subsection{Mechanism of Laser Polishing}

According to onset of laser polishing temperature, the laser feedrate $(v)$ could be changed with the laser input energy $(q)$, namely, when the laser input energy increases, the laser feedrate should be increased correspondingly, vice versa. With a view to improving the efficiency of the laser polishing, saving the energy source, together with decreasing the effect on substrate (DF2), viz., lower laser input energy, the laser polishing feedrate should be higher and the laser input energy should be lower. The three dimensional morphologies of the laser polished surface with various heat-inputs measured by atomic force microscope (AFM) were shown as Fig. 24.

It illustrated that the surface of DF2 steel would not be polished basically (as shown in Fig. 24(a)), when the heat-input interaction with the DF2 steel surface was lower than the heat-input threshold, namely,

where

$$
\mathrm{H}_{\text {input }}<\mathrm{H}_{\text {threshold }}
$$

$\mathrm{H}_{\text {input }}$ stood for the heat-input interaction with the DF2 steel surface, $\mathrm{H}_{\text {threshold }}$ stood for the heat-input threshold.

Figure 24(b) showed the morphology of laser polished surface with heat input threshold, namely, $\mathrm{H}_{\text {input }}=\mathrm{H}_{\text {threshold. }}$. It indicated that the surface was polished successfully, and there were the large amount of micro-pits distributed on the polished surface which could efficiently improve their load carry capacity and permit ease of release (Guo, 2009; Guo, 2007; Jastrzebski, 1987). In addition, it was well known that the morphology of polished surface 
relied on the removal of surface material by evaporation and melting, and its subsequent re-solidification. Due to lower heat-input effecting on substrate, the mechanism of laser polishing during this procedure mainly relied on melting the base metal. When the DF2 steel surface was polished with higher heat-input than the threshold, namely, $\mathrm{H}_{\text {input }}>\mathrm{H}_{\text {threshold, }}$, the morphology of the DF2 steel would be changed correspondingly as shown in Fig. 24(c). The mechanism of laser polishing at the moment was a combination of the base metal vaporizing and melting, the dominant factors of removing the surface material were evaporation and melting both, which was dominant factor relying on the heat-input. If the heat-input was higher, the metal evaporation would dominate the laser polishing procedure. Contrarily, the metal melting would dominate the laser polishing procedure. With the heat-input increasing, namely, $\mathrm{H}_{\text {input }}>>\mathrm{H}_{\text {threshold, }}$, the mechanism of laser polishing would mainly lie on the metal evaporation shown as Fig. 24(d). With the further increasing of the heat-input, namely, $\mathrm{H}_{\text {input }}>>>\mathrm{H}_{\text {threshold, }}$, the surface of DF2 steel would be destroyed thoroughly, shown as Fig. 24(e). There were lots of cracks, craters, protuberances on the polished surface resulted in coarser polished texture led to the poor properties of polished surface.

\section{Conclusions}

Successful polishing DF2 cold work steel was achievable by a Nd:YAG laser with the irradiating parameters set as $\mathrm{P}=1 \mathrm{~J}$, feedrate $=300 \mathrm{~mm} / \mathrm{min}, \mathrm{PD}=3 \mathrm{~ms}, f=20 \sim 25 \mathrm{~Hz}$. Meanwhile, the temperature field of laser polishing was proposed as $T-T_{0}=\frac{\xi \times \eta(N(f, v)) \times q}{R} \exp \left(-\frac{v}{2 \alpha}(R+x)\right)$ and the maximum width of an isothermal enclosure was $\frac{{ }^{\omega_{m}}}{\kappa}=\frac{1}{\omega_{r m}} \exp \left(-\frac{\omega_{r m}}{\omega_{r m}+1}\right)$. Moreover, the mechanism of laser polishing relied on the heat-input interaction with the base metal. When $\mathrm{H}_{\text {input }}=\mathrm{H}_{\text {threshold, }}$, the mechanism of laser polishing was the metal melting; When $\mathrm{H}_{\text {input }}>\mathrm{H}_{\text {threshold, }}$, the mechanism of laser polishing was a combination of metal evaporation and melting; When $\mathrm{H}_{\text {input }}>>\mathrm{H}_{\text {threshold, }}$, the mechanism of laser polishing was the metal evaporation.

\section{Acknowledgements}

This work is supported by City University of Hong Kong General Research Fund (GRF) No. 9041503 and Strategic Research Grant (SRG) No. 7002582.

\section{References}

Duley, W. W. (1983). Laser Processing and Analysis of Materials. New York and London: Plenum Press.

Guo, K. W. (2009). Effect of Polishing Parameters on Morphology of DF2 (AISI-O1) Steel Surface Polished by Nd: YAG Laser. Surface Engineering. 25 (3), 187-195. http://dx.doi.org/10.1179/026708408X336382

Guo, W. (2007). Effect of Irradiation Parameters on Morphology of Polishing DF2 (AISI-O1) Surface by Nd: YAG Laser. Advances in Materials Science and Engineering. http://dx.doi.org/10.1155/2007/51316

Janna, W. S. (1986). Engineering Heat Transfer. Boston: PWS Engineering.

Jastrzebski, Z. D. (1987). The Nature and Properties of Engineering Materials. (3rd ed.). New York: John Wiley $\&$ Sons.

Kurt, S., Wolfgang, R., \& Oskar, P. (1997). Formation of paint surface on different surface structure of steel sheet. Iron and Steel Engineer, 74(3), 43-49.

Lugomer, S. (1990). Laser Technology-Laser Driven Processes. Englewood Cliffs, N. J.: Prentice Hall Inc.

Mills, A. F. (1995). Heat and Mass Transfer. Chicago: P. R. Donnelly \& Sons Company.

Ryk, G., Kligerman, Y., \& Etson, I. (2002). Experimental investigation of laser surface texturing for reciprocating automotive components. Tribology Transactions. 45(4), 444-449. http://dx.doi.org/10.1080/10402000208982572

Steen, W. M. (2003). Laser Material Processing. (3rd ed.). London: Springer-Verlag. 
Table 1. Chemical composition of DF2 cold work steel

\begin{tabular}{cccccccc}
\hline Element & $\mathrm{C}$ & $\mathrm{Si}$ & $\mathrm{Mn}$ & $\mathrm{Cr}$ & $\mathrm{W}$ & $\mathrm{V}$ & $\mathrm{Fe}$ \\
\hline (Wt.\%) & 0.9 & 0.3 & 1.2 & 0.5 & 0.5 & 0.1 & Bal. \\
\hline
\end{tabular}

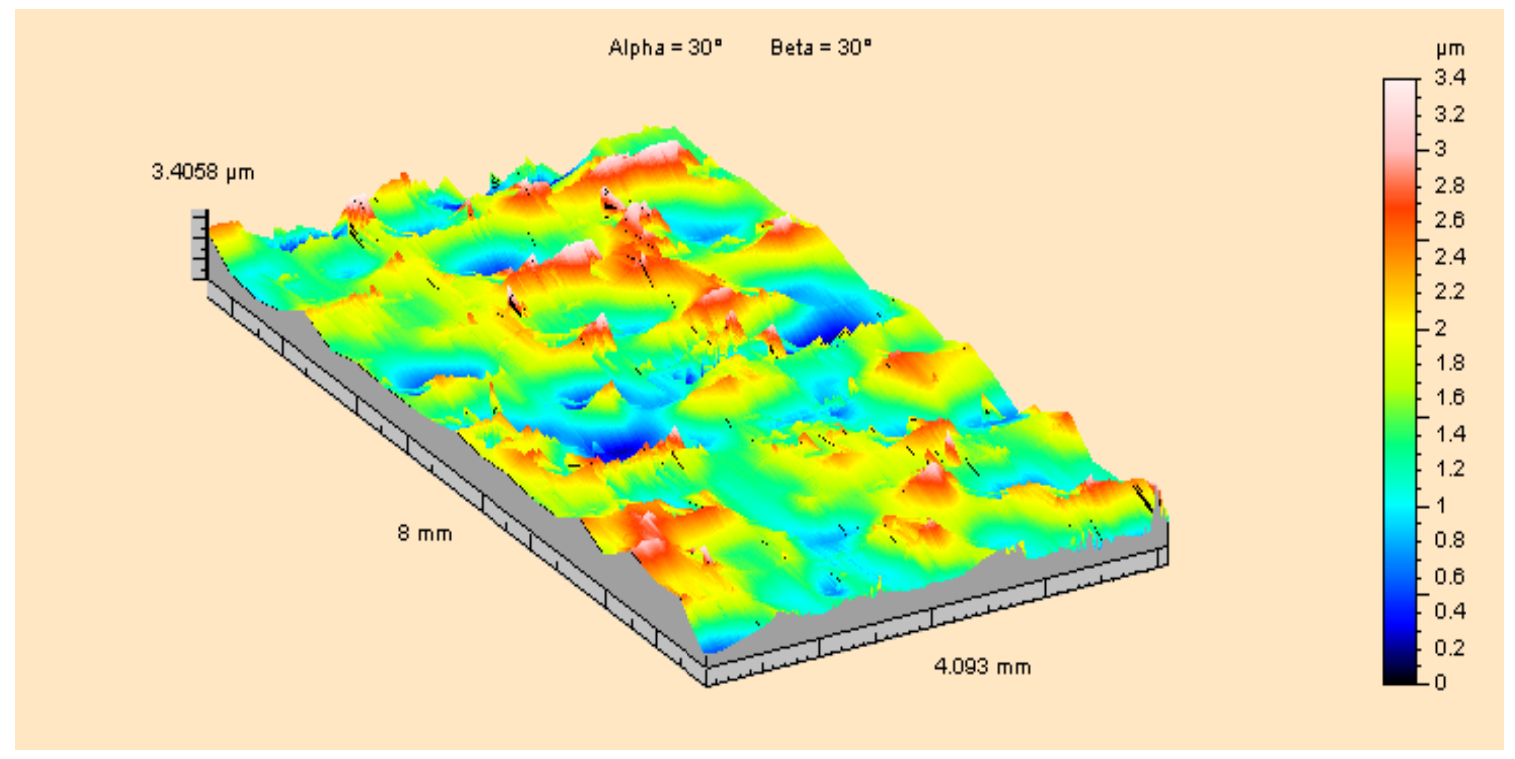

(a) Initial morphology of specimen

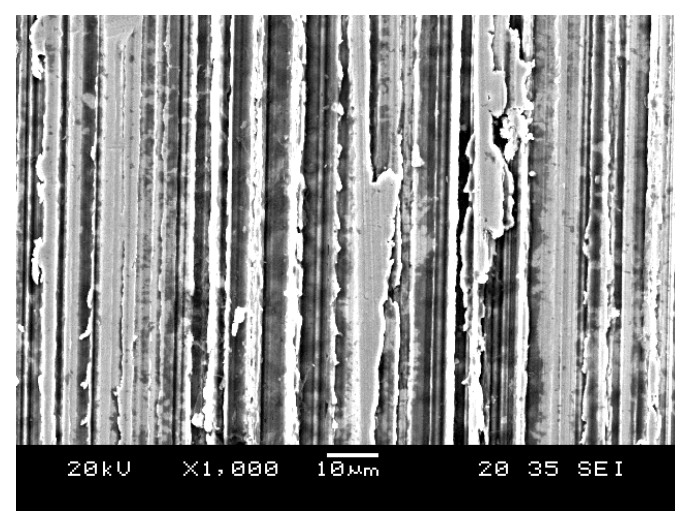

(b) SEM of the initial surface

Figure 1. Morphology and its corresponding SEM of the initial surface $(R \mathrm{a}=0.4 \mu \mathrm{m})$ 




Figure 2. Microstructure of DF2 steel (AISI-O1)

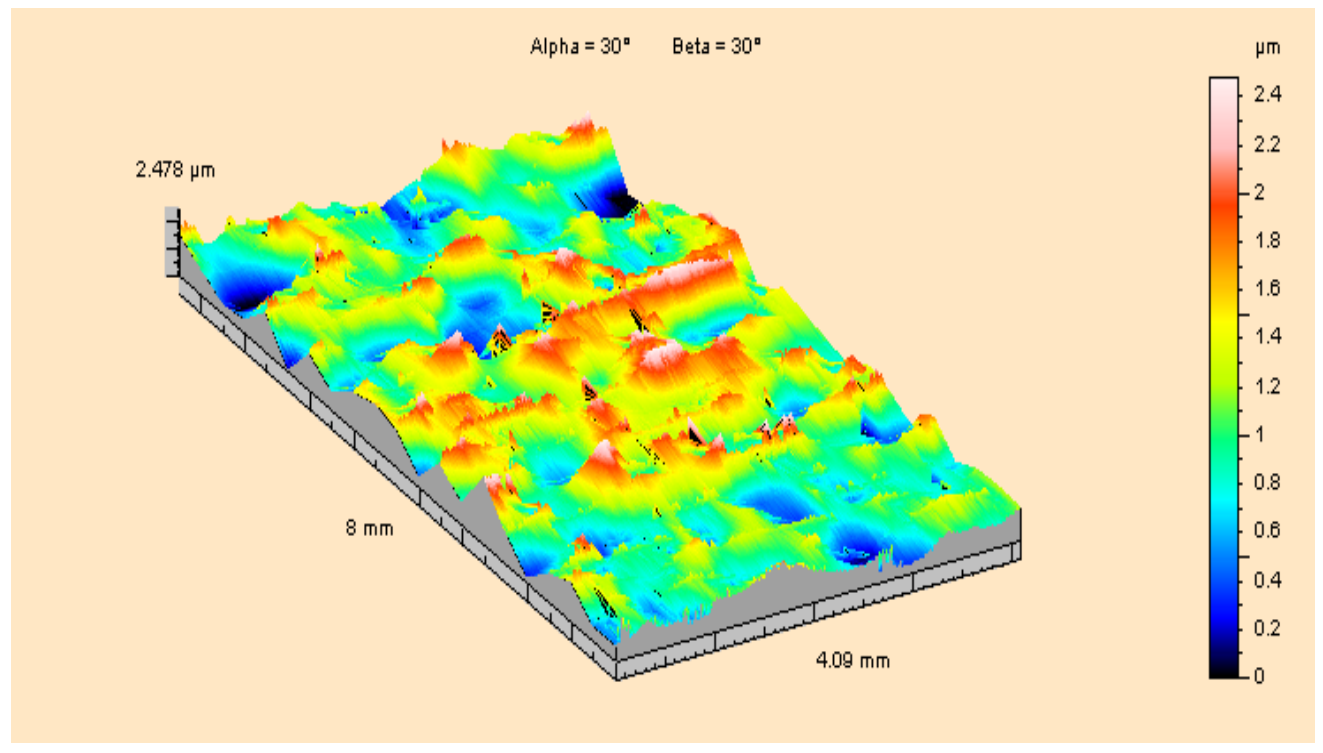

(a) $400 \mathrm{~mm} / \mathrm{min}$

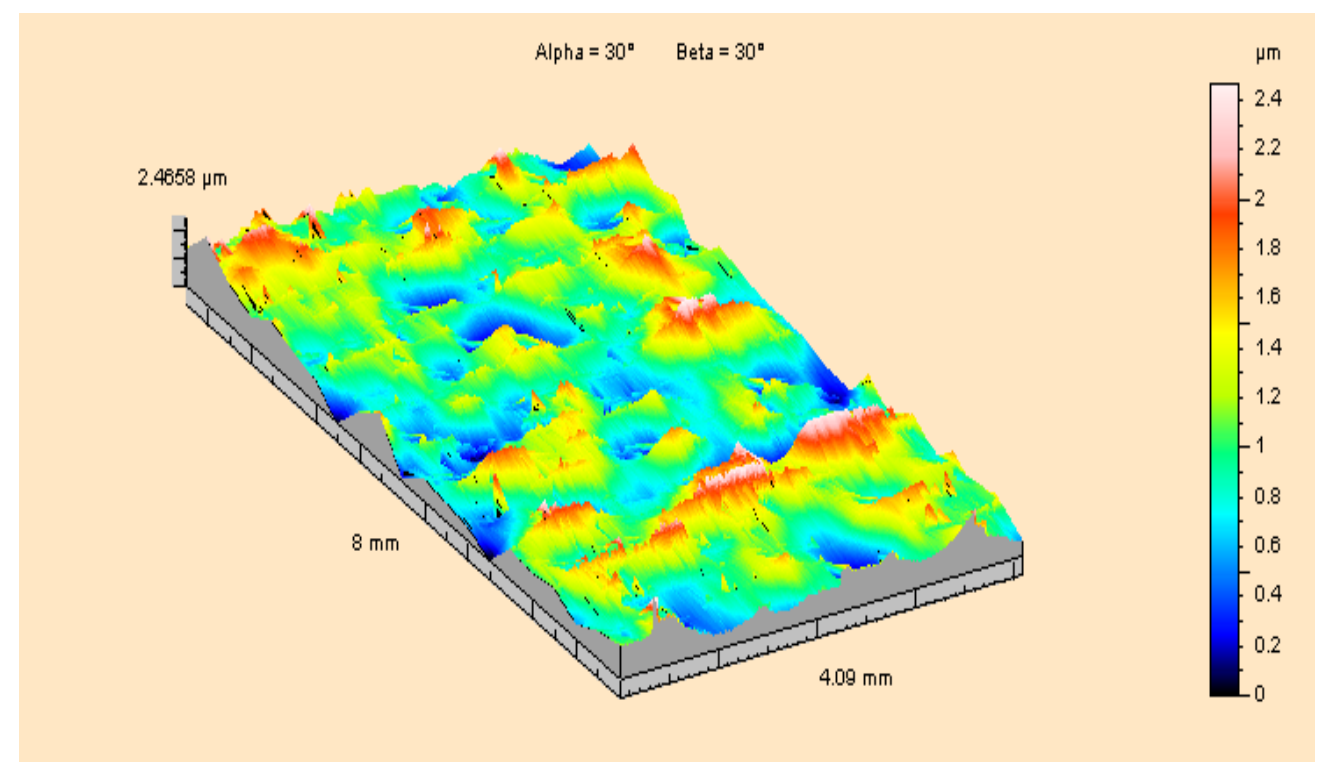

(b) $300 \mathrm{~mm} / \mathrm{min}$ 


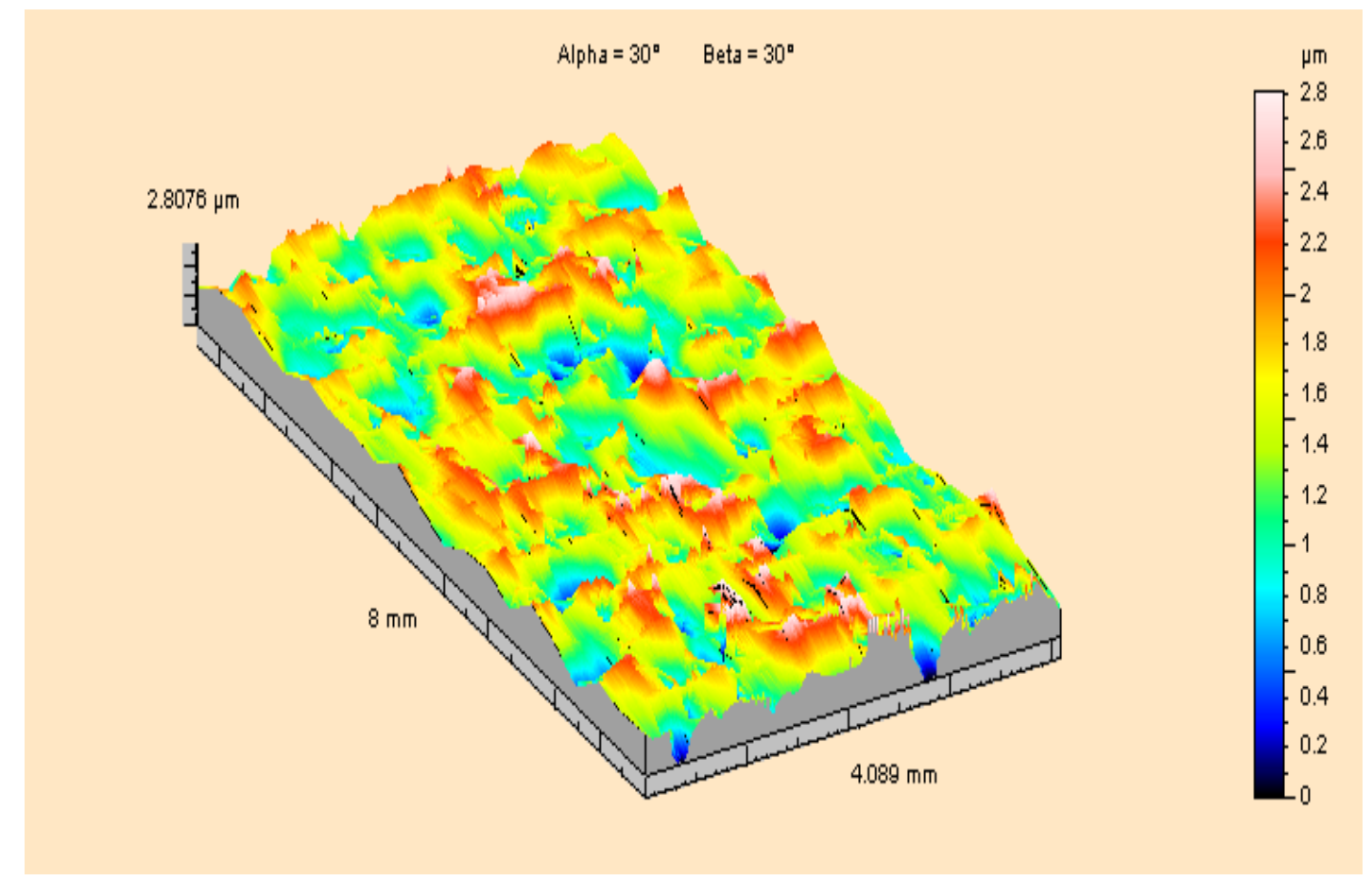

(c) $200 \mathrm{~mm} / \mathrm{min}$

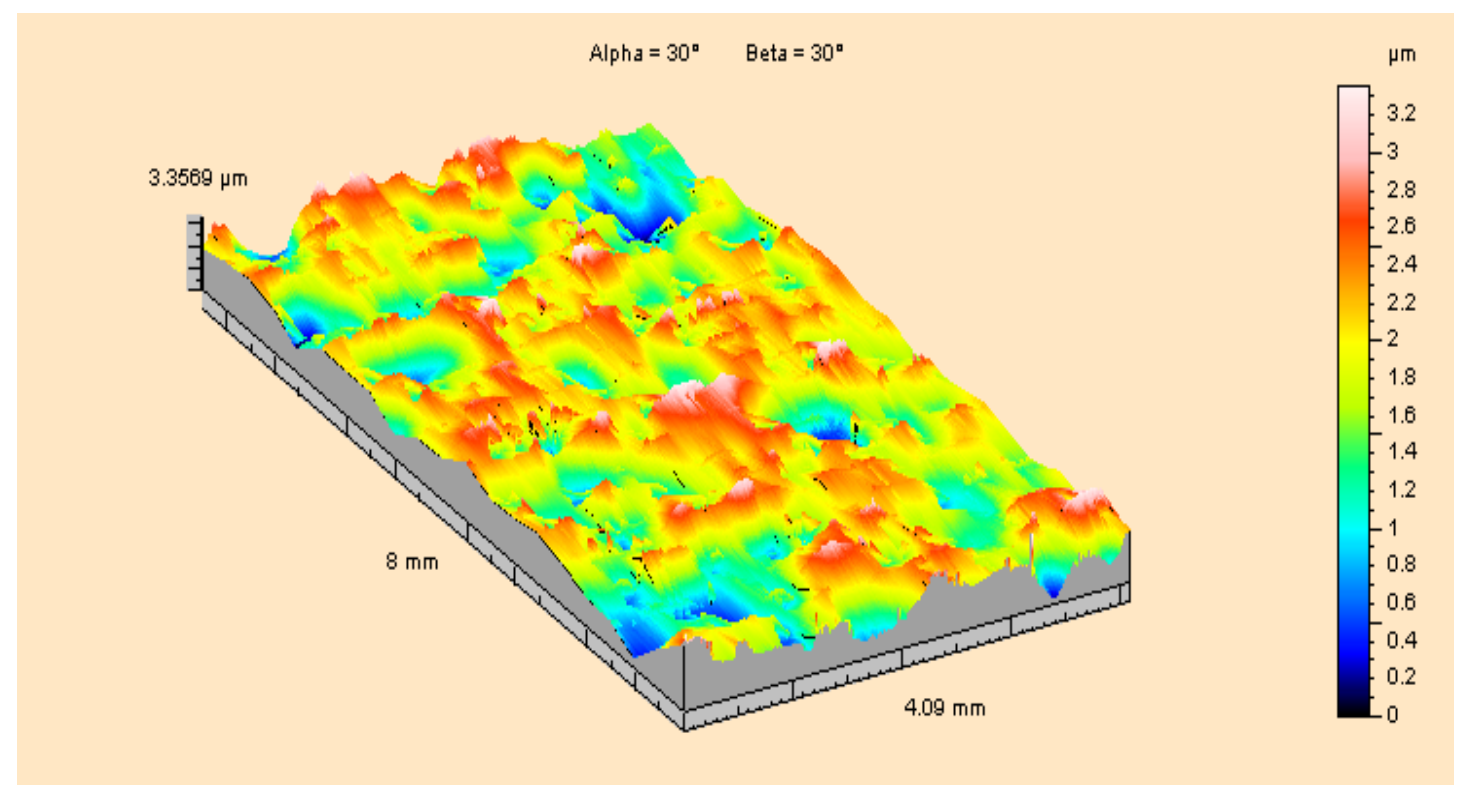

(d) $100 \mathrm{~mm} / \mathrm{min}$

$R \mathrm{a}=0.4 \mu \mathrm{m}$, Pulse energy $=1 \mathrm{~J}, f=25 \mathrm{~Hz}, \mathrm{PD}=3 \mathrm{~ms}$

Figure 3. Surface Textures of laser polishing at various feedrates 


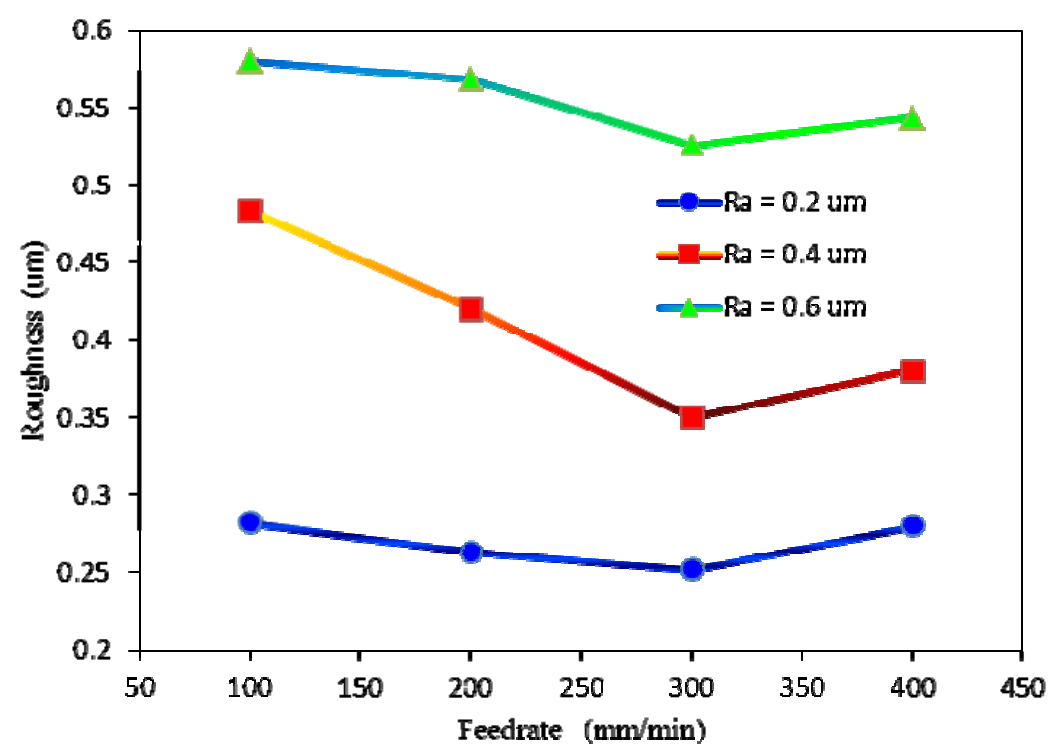

Figure 4. Relationship between $R \mathrm{a}$ and feedrates

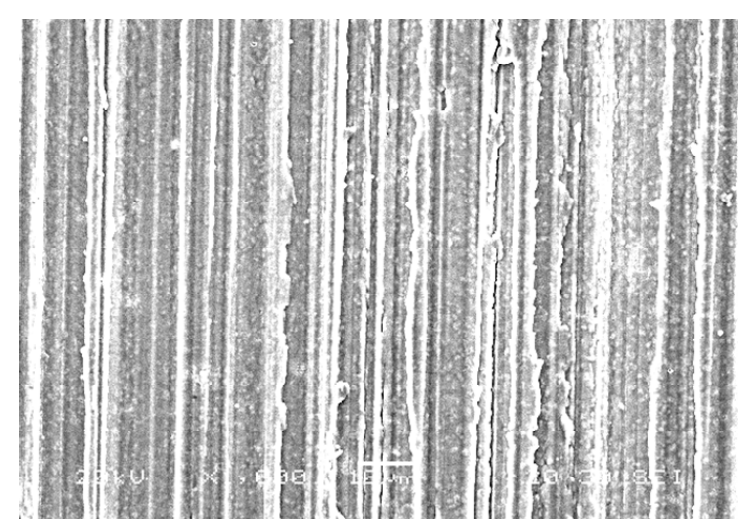

(a)
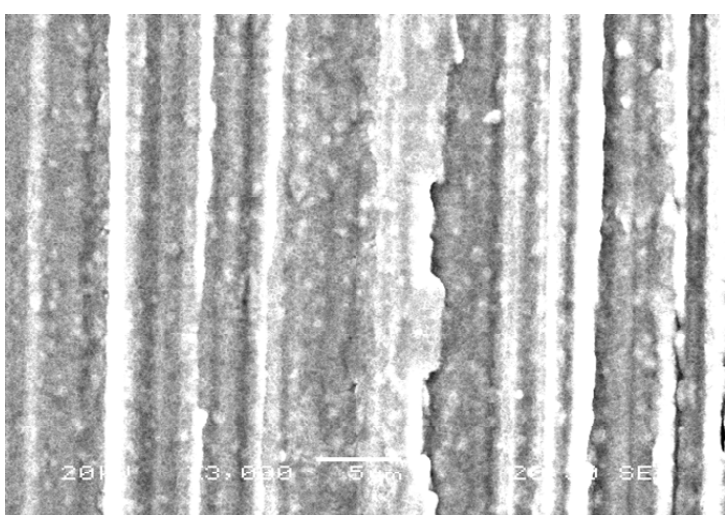

(b)

Pulse energy $=2 \mathrm{~J}$

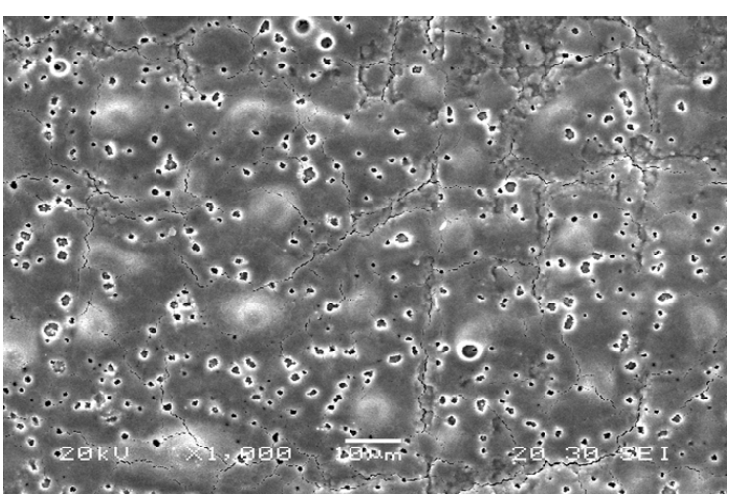

(c)

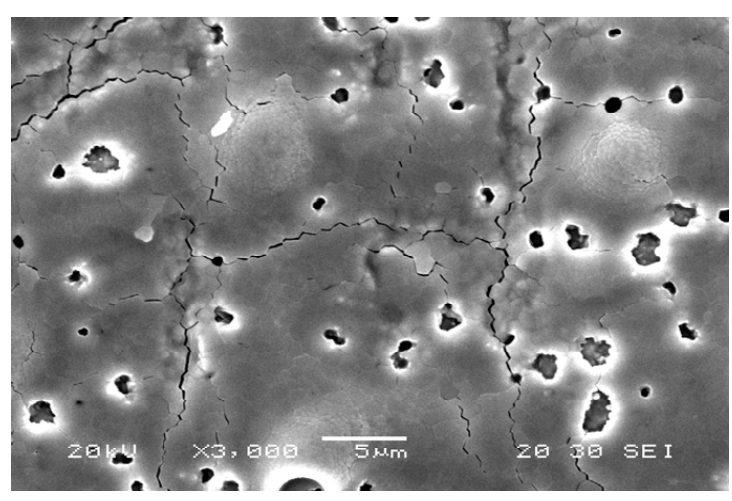

(d)

Pulse energy $=3 \mathrm{~J}$

$R \mathrm{a}=0.4 \mu \mathrm{m}$, feedrate $=300 \mathrm{~mm} / \mathrm{min}, f=25 \mathrm{~Hz}, \mathrm{PD}=3 \mathrm{~ms}$

Figure 5. SEM of laser polishing surface topographies at various pulse energies 


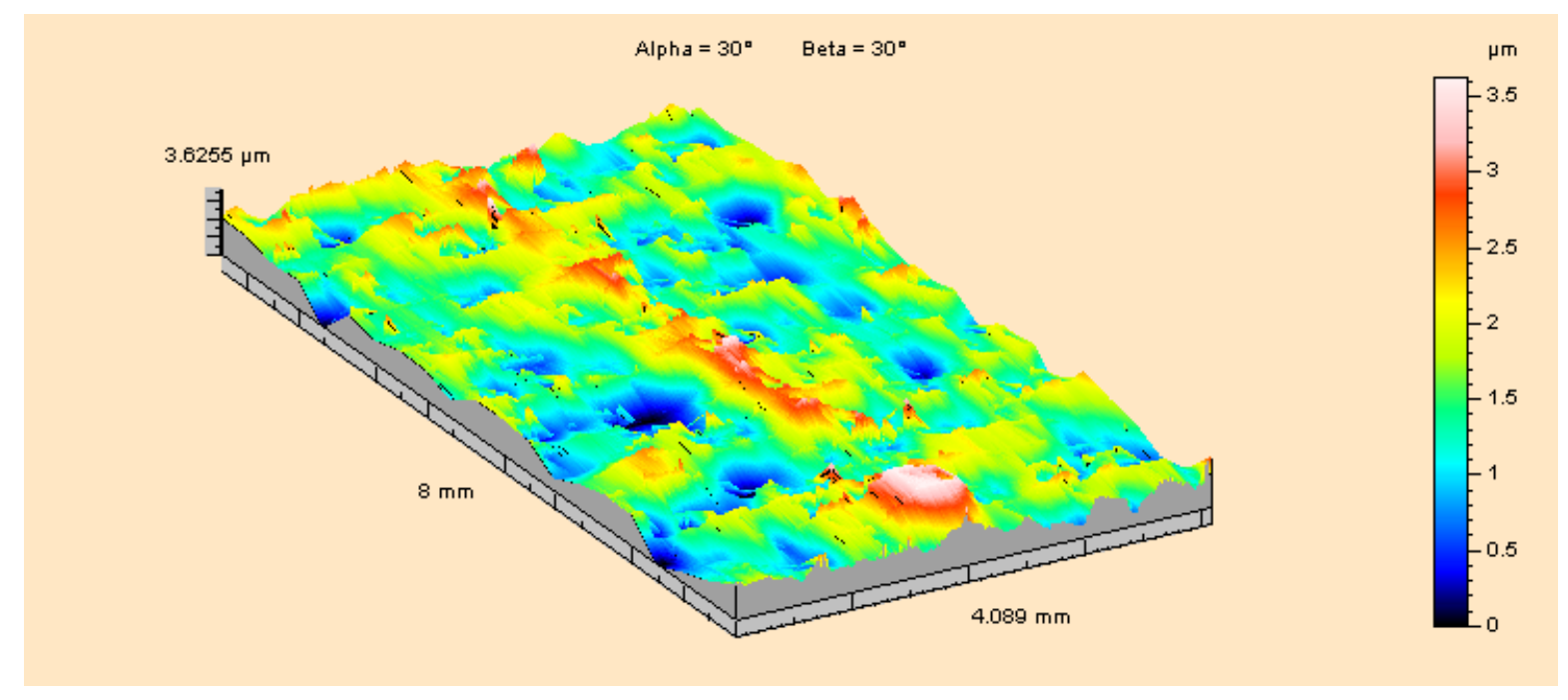

(a) Pulse energy $=2 \mathrm{~J}$

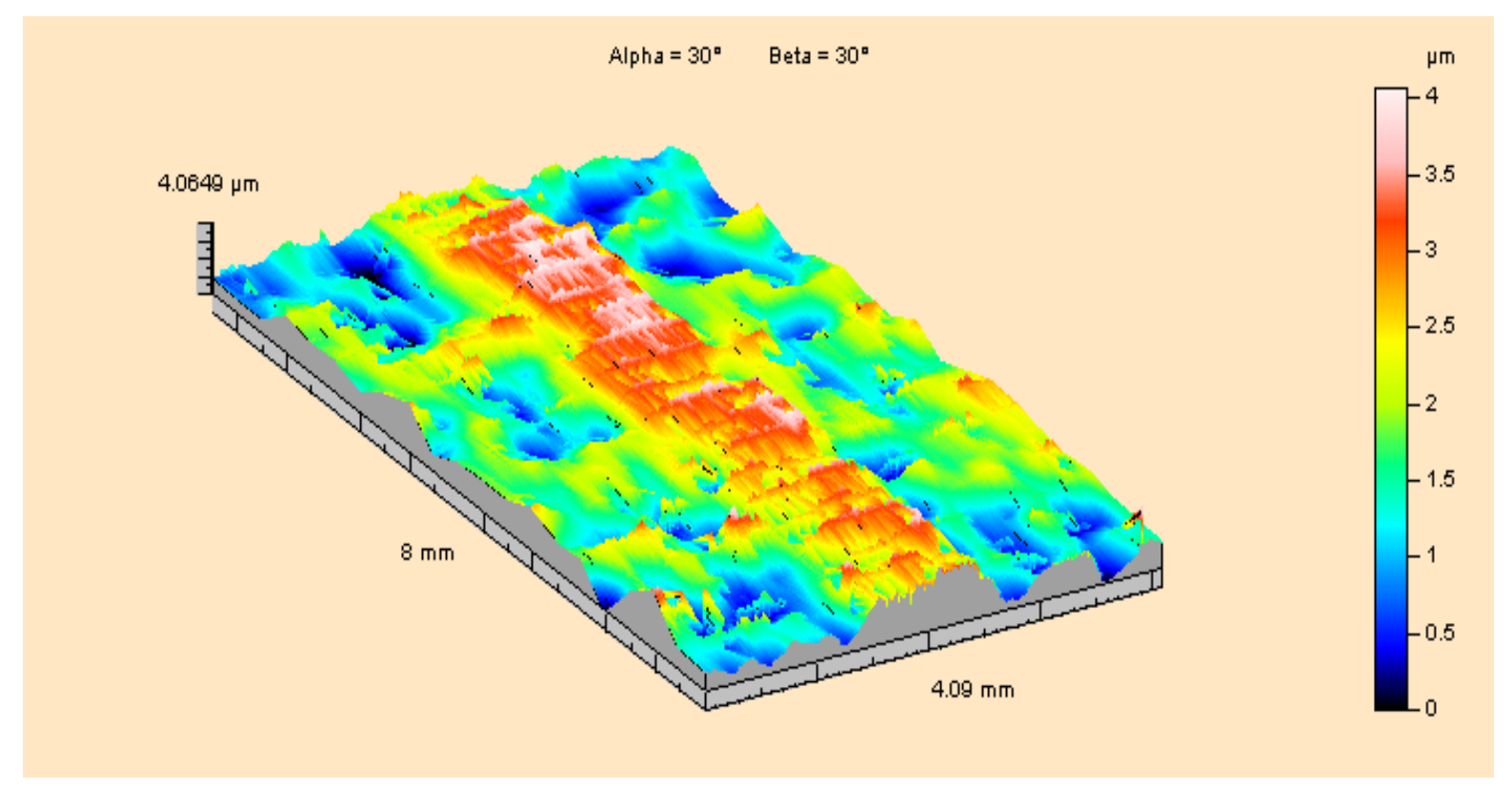

(b) Pulse energy $=3 \mathrm{~J}$

$\mathrm{Ra}=0.4 \mu \mathrm{m}$, feedrate $=300 \mathrm{~mm} / \mathrm{min}, f=25 \mathrm{~Hz}, \mathrm{PD}=3 \mathrm{~ms}$

Figure 6. Surface textures of laser polishing at various pulse energies 


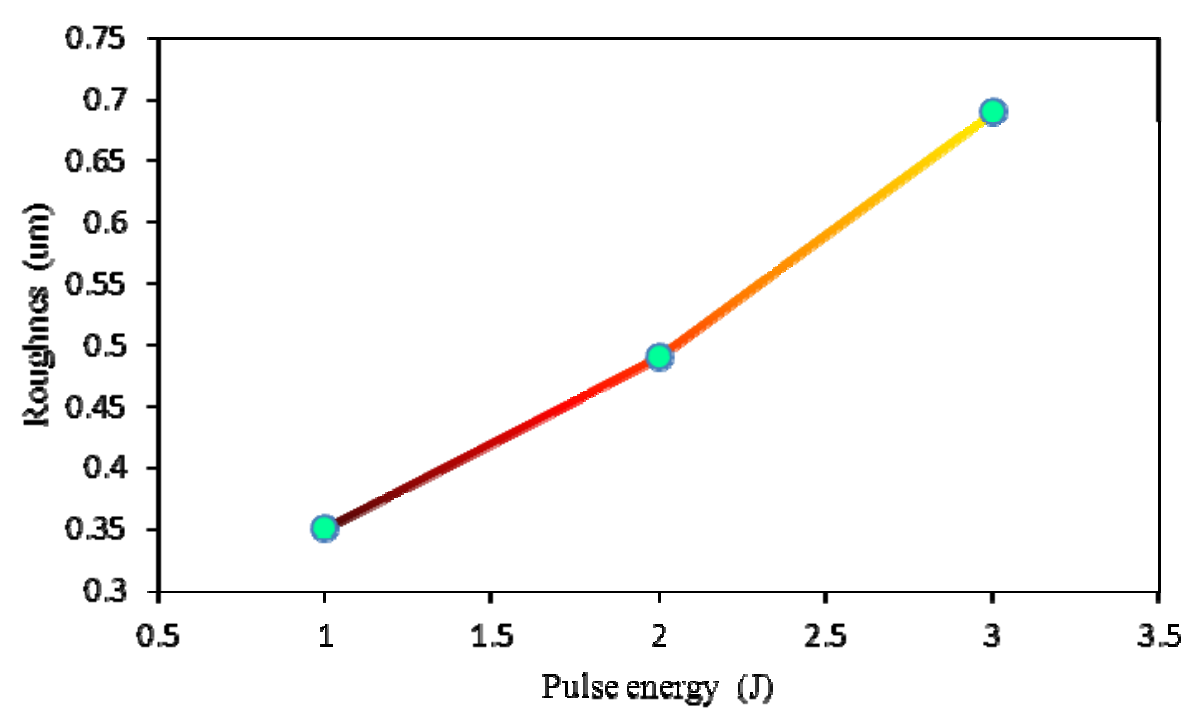

Figure 7. Relationship between $R \mathrm{a}$ and pulse energy

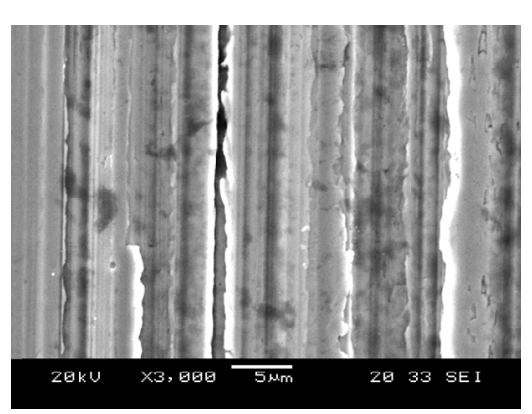

(a) $f=30 \mathrm{~Hz}$

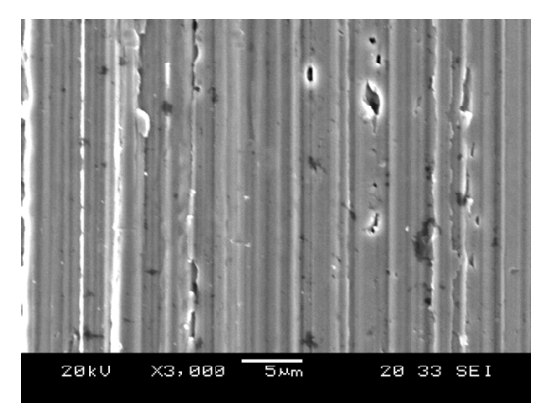

(c) $f=20 \mathrm{~Hz}$

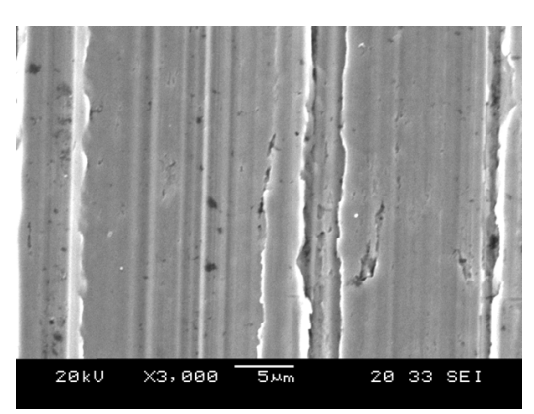

(b) $f=25 \mathrm{~Hz}$



(d) $f=15 \mathrm{~Hz}$

$R \mathrm{a}=0.4 \mu \mathrm{m}$, Pulse energy $=1 \mathrm{~J}$, feedrate $=300 \mathrm{~mm} / \mathrm{min}, \mathrm{PD}=3 \mathrm{~ms}$

Figure 8 . SEM of laser polishing surface topographies at various pulse frequencies 


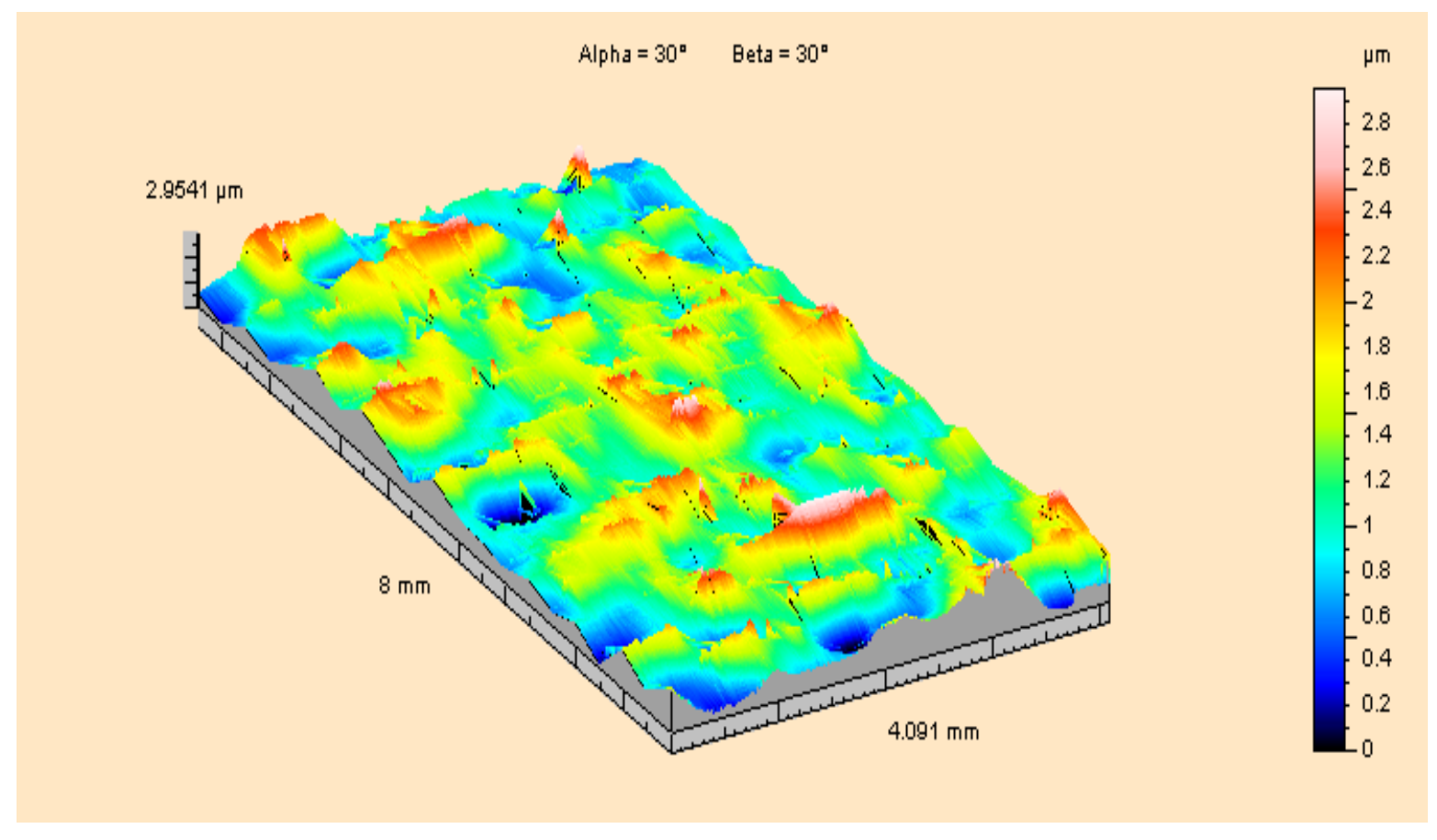

(a) $f=30 \mathrm{~Hz}$

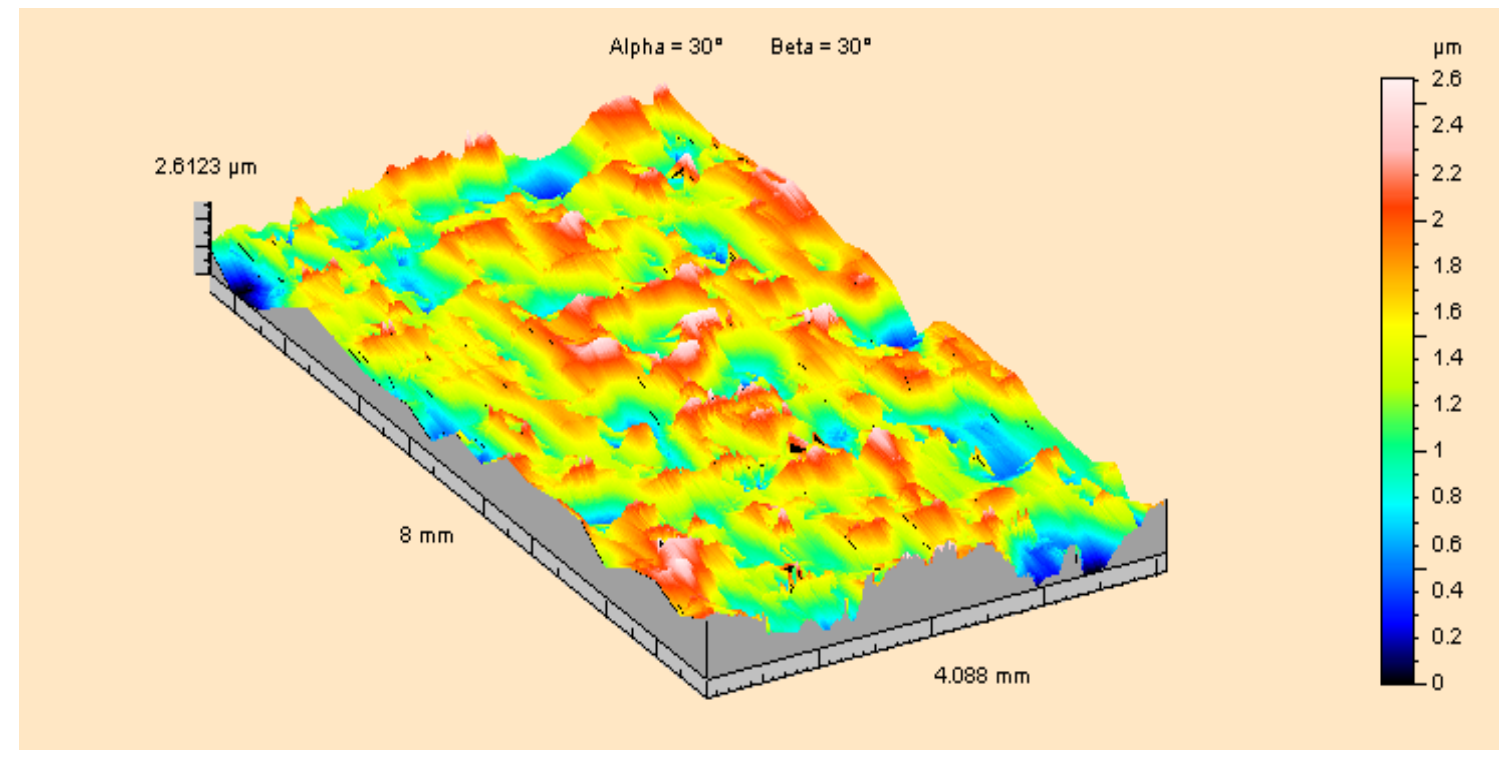

(b) $f=20 \mathrm{~Hz}$ 


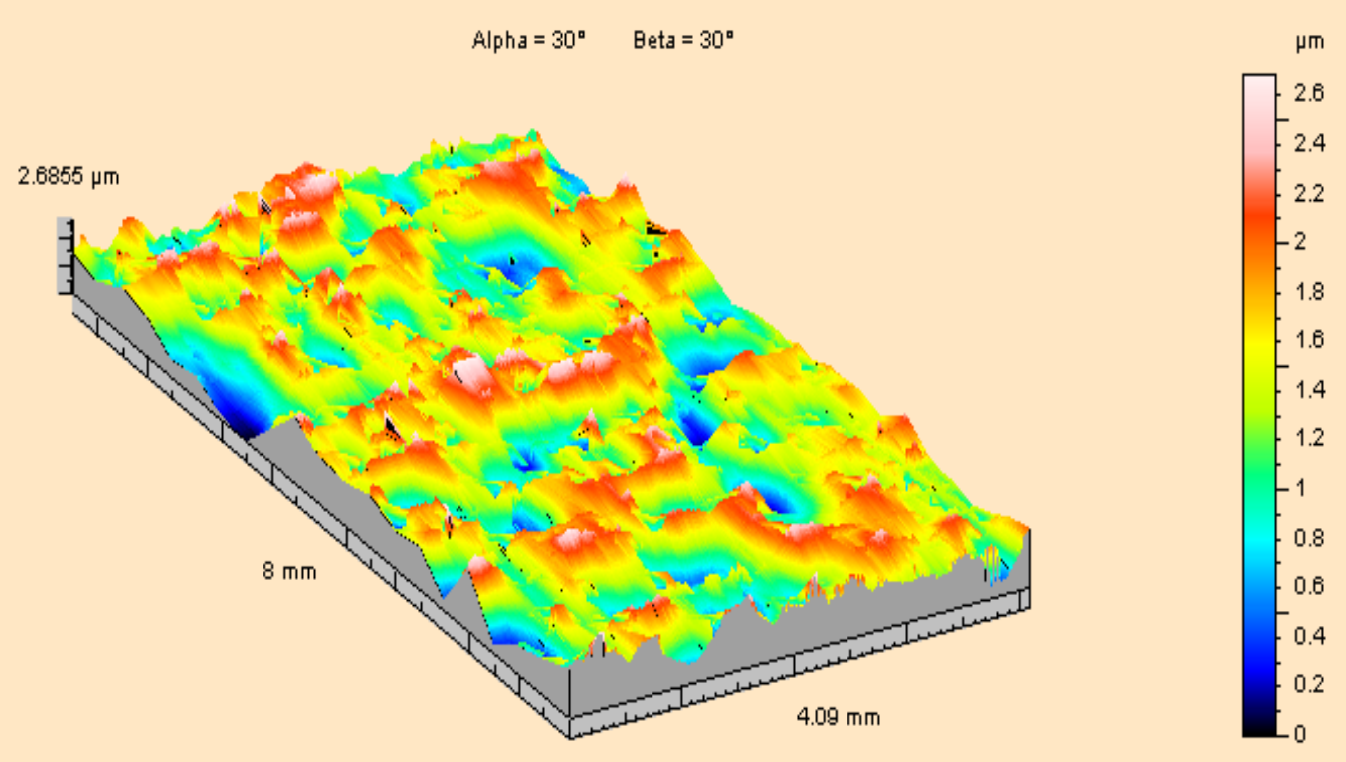

(c) $f=15 \mathrm{~Hz}$

$R \mathrm{a}=0.4 \mu \mathrm{m}$, Pulse energy $=1 \mathrm{~J}$, feedrate $=300 \mathrm{~mm} / \mathrm{min}, \mathrm{PD}=3 \mathrm{~ms}$

Figure 9. Surface textures of laser polishing at various pulse frequencies

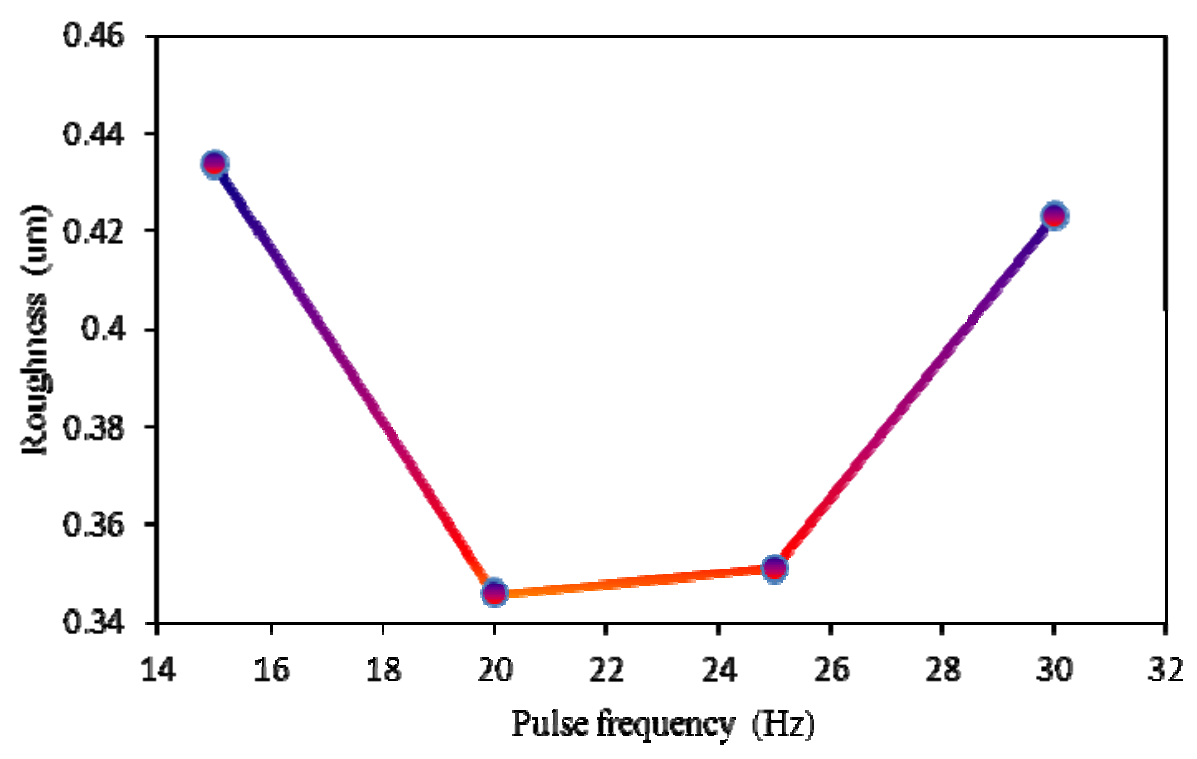

Figure 10. Relationship between $R \mathrm{a}$ and pulse frequencies 


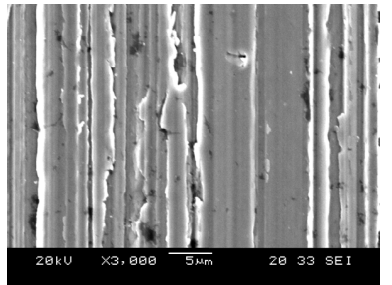

(a) $\mathrm{PD}=2 \mathrm{~ms}$

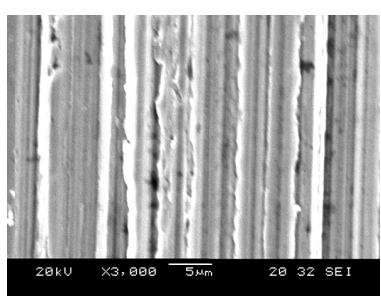

(d) $P D=5 \mathrm{~ms}$

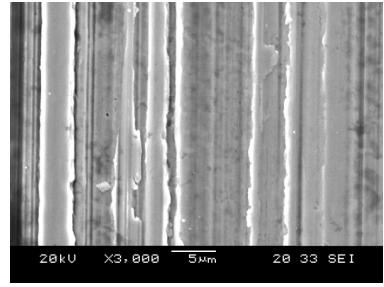

(b) $\mathrm{PD}=3 \mathrm{~ms}$

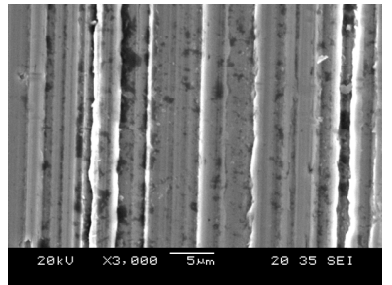

(c) $\mathrm{PD}=4 \mathrm{~ms}$

$R \mathrm{a}=0.4 \mu \mathrm{m}$, Pulse energy $=1 \mathrm{~J}$, feedrate $=300 \mathrm{~mm} / \mathrm{min}, f=20 \mathrm{~Hz}$

Figure 11. SEM of laser polishing surface topographies at various pulse durations

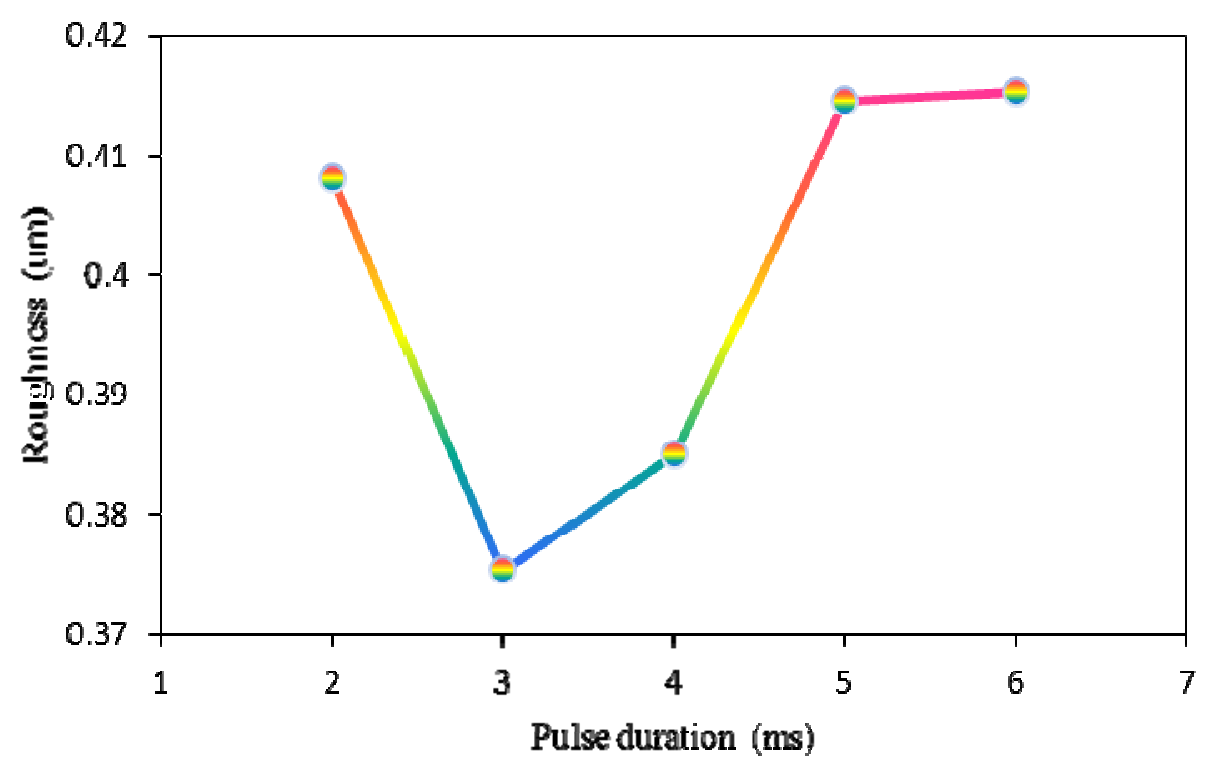

Figure 12. Relationship between $R \mathrm{a}$ and pulse duration 




(a) Morphology of the polished surface

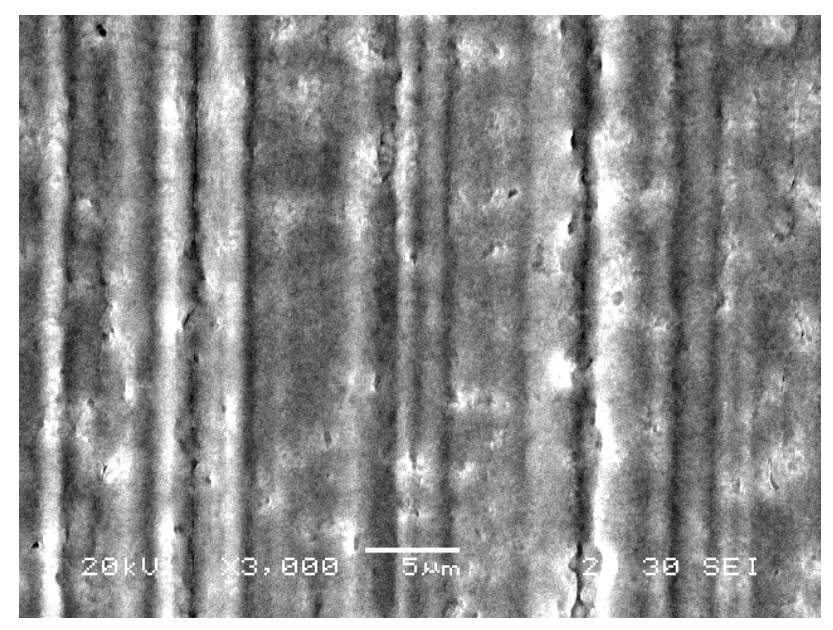

(b) SEM of the polished surface

Figure 13. Morphology and its corresponding SEM of the polished surface 


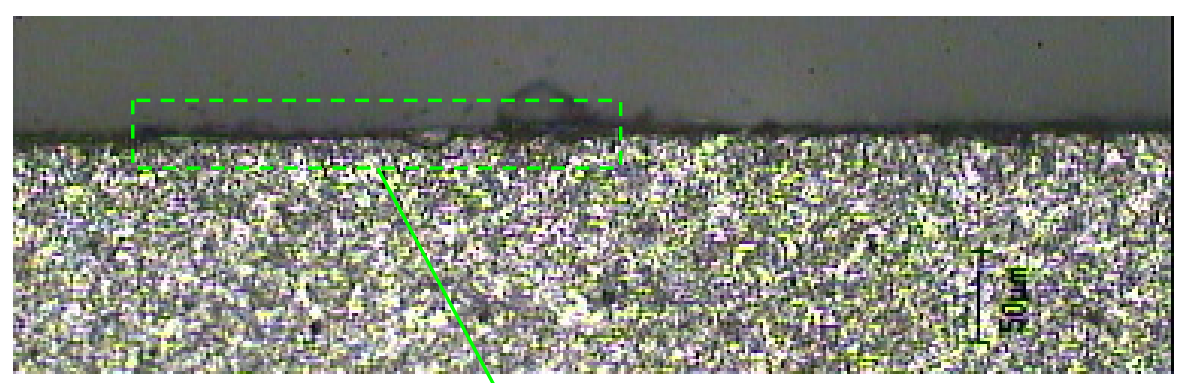

(a)

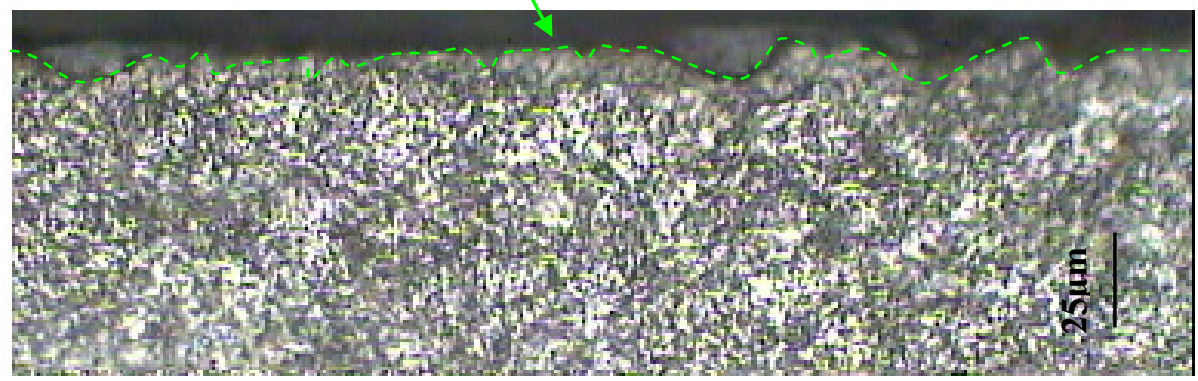

(b)

Figure 14. Initial cross-section microstructure of the specimen

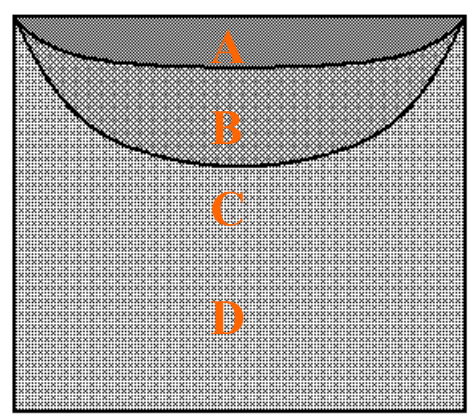

Figure 15. Schematic illustration of cross-section of polished specimen 


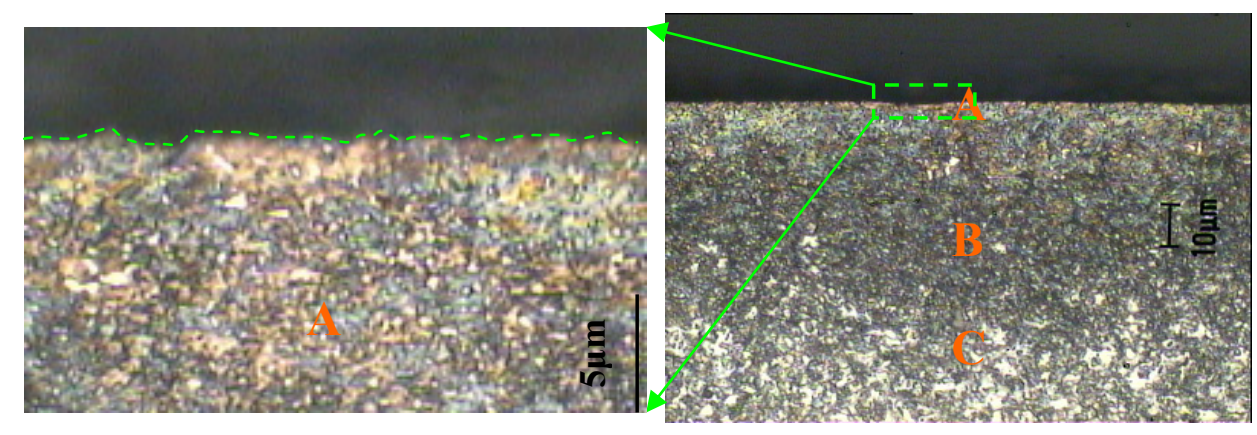

(a)

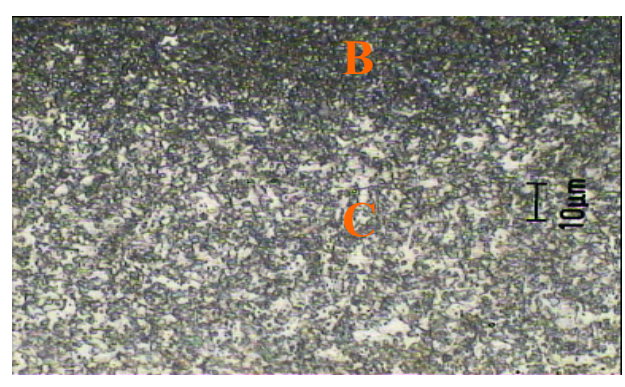

(b)

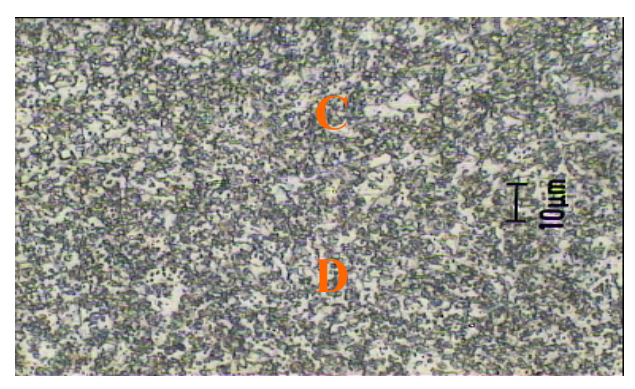

(c)

Figure 16. Cross-section microstructures of polished specimen

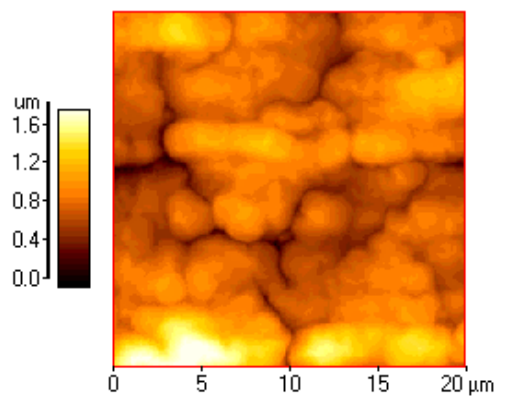

Figure 17. Surface textures of laser polished surface 


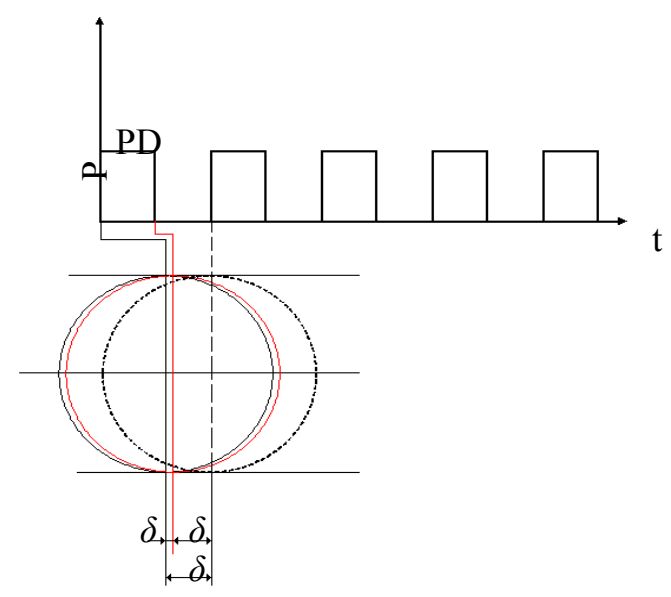

Figure 18. Schematic image of a laser pulse irradiated on the surface

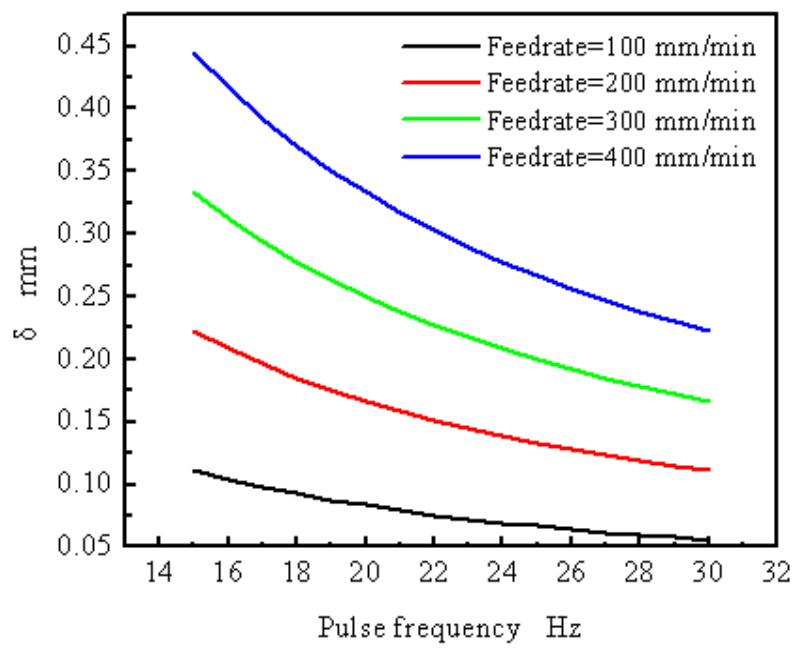

Figure 19. Relationship between $\delta$ and pulse frequency at various feedrates

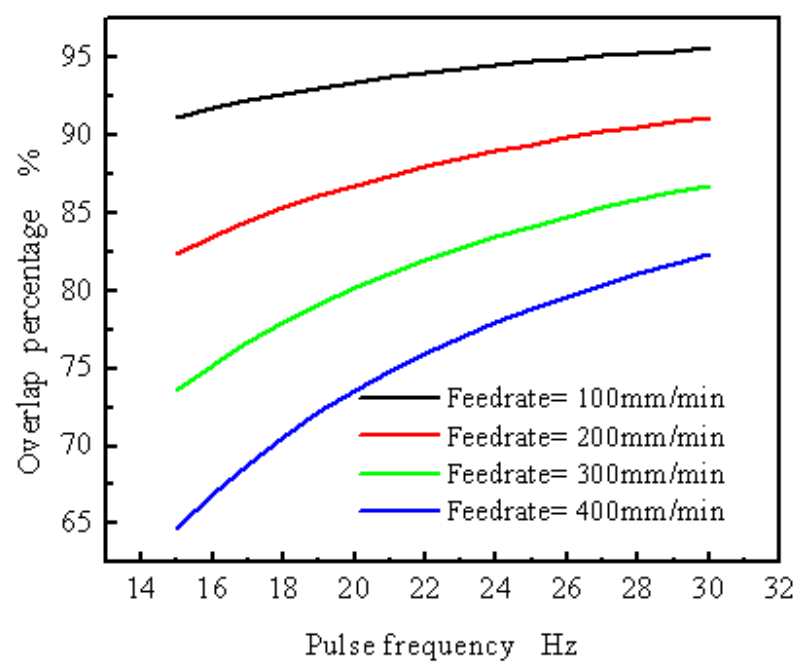

Figure 20. Relationship between overlap percentage and pulse frequency at various feedrates 


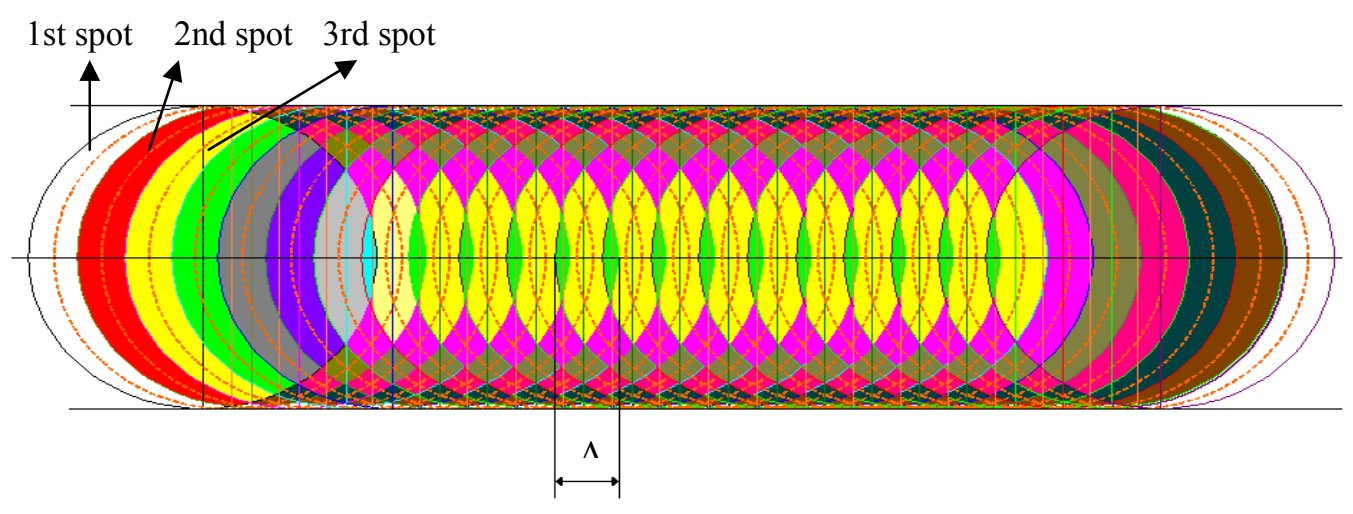

Figure 21. Schematic diagram of laser polishing

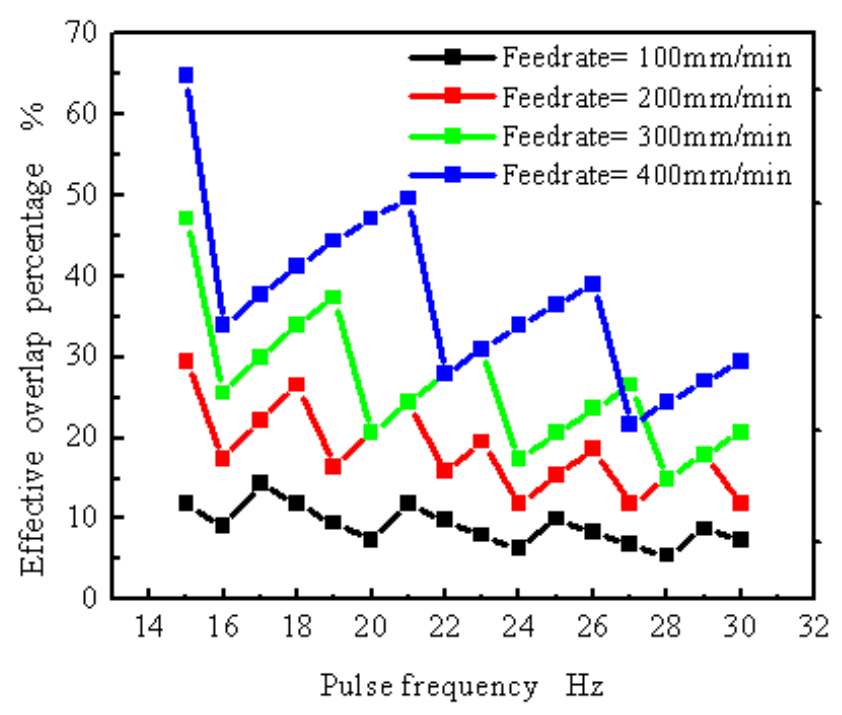

Figure 22. Relationship between effective overlap percentage and pulse frequency at various feedrates

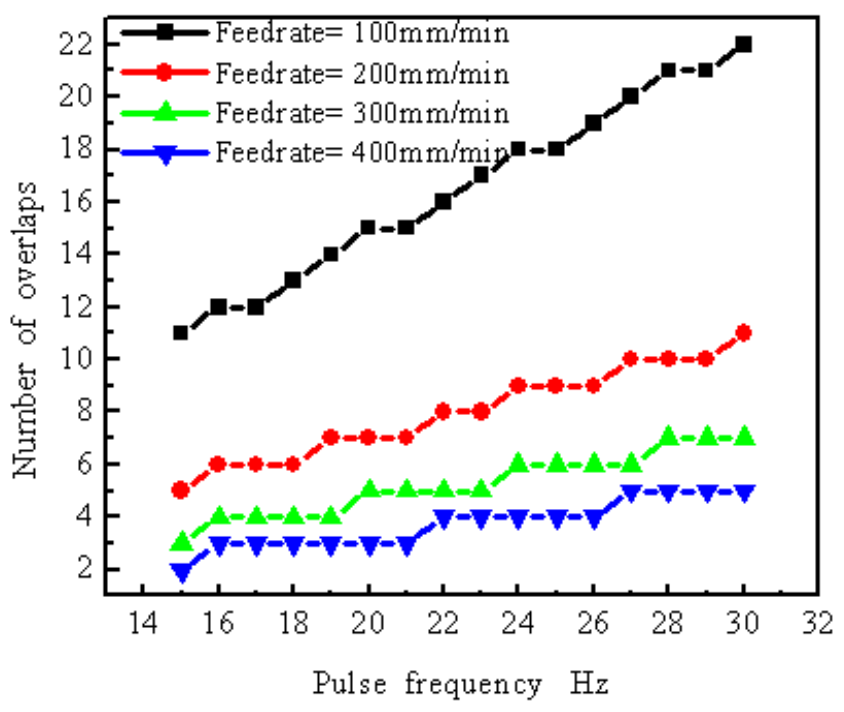

Figure 23. Relationship between number of overlaps and pulse frequency at various feedrates 


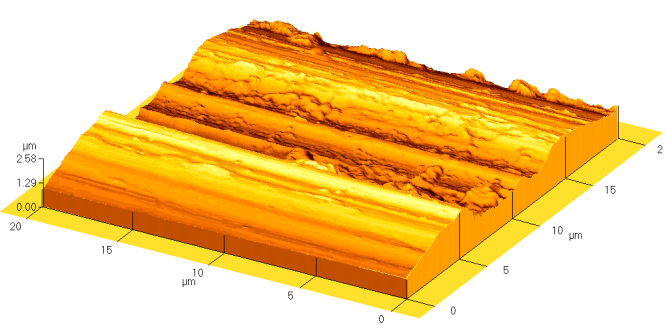

(a) Laser polished DF2 steel with Heat-input lower than threshold

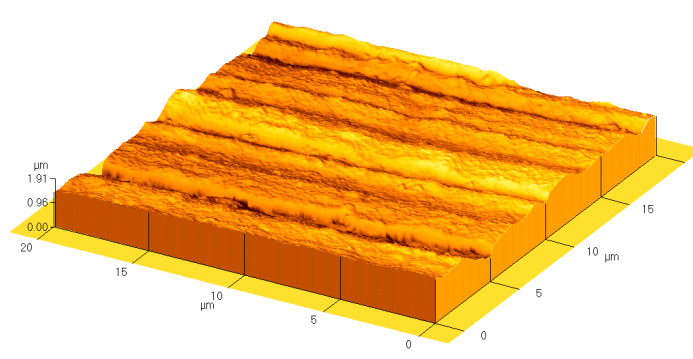

(c) Laser polished DF2 steel with Heat-input higher than threshold

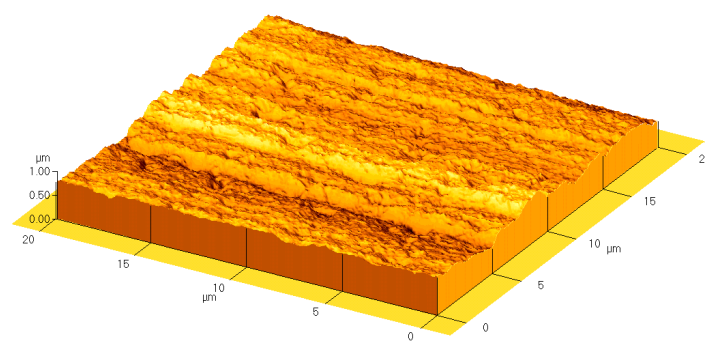

(b) Laser polished DF2 steel with Heat-input threshold

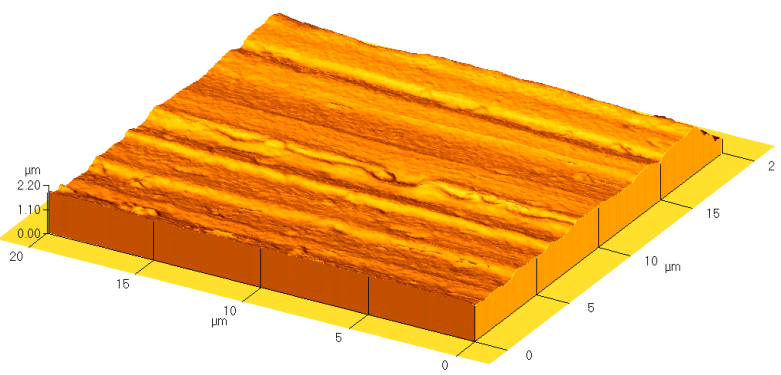

(d) Laser polished DF2 steel with Heat-input higher than (c)

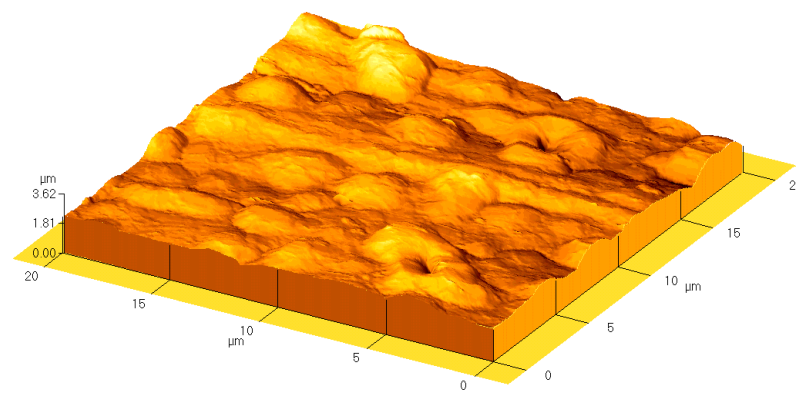

(e) Laser polished DF2 steel with Heat-input higher than (d)

Figure 24. 3D morphologies of laser polished surface 